\title{
I 6th International Congress on Antiphospholipid Antibodies Task Force Report on Antiphospholipid Syndrome Treatment Trends
}

\author{
Hannah Cohen ${ }^{1,2}$ (D, Maria J Cuadrado ${ }^{3}$, Doruk Erkan ${ }^{4}$, \\ Ali Duarte-Garcia ${ }^{5,6}$ (D), David A Isenberg ${ }^{2,7}$ (D), Jason S Knight ${ }^{8}$, \\ Thomas L Ortel ${ }^{9}$, Anisur Rahman ${ }^{7}$, Jane E Salmon ${ }^{10}$, \\ Maria G Tektonidou ' (D, David J Williams ${ }^{2,12}$, Rohan Willis ${ }^{13}$, \\ Scott C Woller ${ }^{14}$ (D) and Danieli Andrade ${ }^{15}$
}

\begin{abstract}
Antiphospholipid syndrome (APS), an acquired autoimmune thrombophilia, is characterised by thrombosis and/or pregnancy morbidity in association with persistent antiphospholipid antibodies. The 16th International Congress on Antiphospholipid Antibodies Task Force on APS Treatment Trends reviewed the current status with regard to existing and novel treatment trends for APS, which is the focus of this Task Force report. The report addresses current treatments and developments since the last report, on the use of direct oral anticoagulants in patients with APS, antiplatelet agents, adjunctive therapies (hydroxychloroquine, statins and vitamin D), targeted treatment including rituximab, belimumab, and anti-TNF agents, complement inhibition and drugs based on peptides of beta2-glycoprotein I. In addition, the report summarises potential new players, including coenzyme Q I0, adenosine receptor agonists and adenosine potentiation. In each case, the report provides recommendations for clinicians, based on the current state of the art, and suggests a clinical research agenda. The initiation and development of appropriate clinical studies requires a focus on devising suitable outcome measures, including a disease activity index, an optimal damage index, and a specific quality of life index.
\end{abstract}

\section{Keywords}

Antiphospholipid syndrome, direct oral anticoagulants, biologics, complement inhibition, anti- $\beta 2$-glycoprotein I peptides, potential new players

Date received: 18 July 2020; accepted: 24 July 2020

\footnotetext{
'Haemostasis Research Unit, Department of Haematology, University College London, London, UK

${ }^{2}$ University College London Hospitals NHS Foundation Trust, London, UK

${ }^{3}$ Rheumatology Department, Clinica Universidad de Navarra, Madrid, Spain

${ }^{4}$ Barbara Volcker Center for Women and Rheumatic Disease, Hospital for Special Surgery, Weill Cornell Medicine, New York, NY, USA

${ }^{5}$ Division of Rheumatology, Department of Internal Medicine, Mayo

Clinic, Rochester, Minnesota, USA

${ }^{6}$ Robert D. and Patricia E. Kern Center for the Science of Health Care

Delivery, Mayo Clinic, Rochester, Minnesota, USA

${ }^{7}$ Centre for Rheumatology, Division of Medicine, University College London, London, UK

${ }^{8}$ Division of Rheumatology, University of Michigan, Ann Arbor, Michigan, USA
}

\footnotetext{
${ }^{9}$ Division of Hematology, Department of Medicine, and Department of Pathology, Duke University Medical Center, Durham, NC, USA

${ }^{10}$ Division of Rheumatology, Hospital for Special surgery, Weill Cornell Medicine, New York, NY, USA

${ }^{\prime \prime}$ First Department of Propaedeutic Internal Medicine, National and

Kapodistrian University of Athens, Athens, Greece

${ }^{12}$ UCL EGA Institute for Women's Health, University College London, London, UK

${ }^{13}$ Antiphospholipid Standardization Laboratory, University of Texas Medical Branch, Galveston, TX, USA

${ }^{14}$ Department of Medicine, Intermountain Medical Center, Murray UT; Division of General Internal Medicine, University of Utah School of Medicine, Salt Lake City, UT, USA

${ }^{15}$ University of São Paulo, São Paulo, Brazil
}

Corresponding author:

Hannah Cohen, Haemostasis Research Unit, Department of Haematology, University College London, Ist Floor, 5 I Chenies Mews, London WCIE 6HX, UK.

Email: hannah.cohen@ucl.ac.uk 


\section{Introduction}

Antiphospholipid syndrome (APS), an acquired autoimmune thrombophilia, is characterised by thrombosis and/or pregnancy morbidity in association with persistent antiphospholipid antibodies (aPL; lupus anticoagulant [LA], and $\operatorname{IgG} / \operatorname{IgM}$ anticardiolipin $[\mathrm{aCL}]$ and anti-beta-2-glycoprotein I $\left.\left[\mathrm{a} \beta_{2} \mathrm{GPI}\right]\right)^{1} \quad$ Triple aPLpositive denotes the presence of all three aPL, i.e. LA, aCL and $a \beta_{2}$ GPI. The overall prevalence of APS has been estimated at 50 per 100,000 people, ${ }^{2}$ with a female-to-male ratio of approximately $5: 1 .^{3}$ Thrombosis, a cardinal disease manifestation, may be venous, arterial, or microvascular. APS-associated pregnancy morbidity includes recurrent early miscarriages, fetal death after 10 weeks' gestation, and premature delivery before 34 weeks' gestation because of pre-eclampsia/eclampsia or placental insufficiency, which leads to fetal growth restriction. ${ }^{1}$

Non-criteria manifestations, that are usually refractory to standard APS treatment of anticoagulation with a vitamin $\mathrm{K}$ antagonist (VKA), include livedo reticularis, thrombocytopenia, hemolytic anemia, aPL-related cardiac valve disease and nephropathy, skin ulcers, and cognitive dysfunction. ${ }^{1}$ Catastrophic APS (CAPS), the most severe form of APS with a high overall mortality rate of $37 \%$, is associated with multiple small vessel thromboses. ${ }^{4}$ Although all these clinical manifestations are grouped as a single entity of APS, there may be individual differences in disease pathogenesis. Patients with CAPS who receive anticoagulation in combination with glucocorticoid plus plasma exchange and/or intravenous immunoglobulin, have the highest survival rate (mortality rate $28.6 \%$ ). ${ }^{4}$ In other APS patients with small vessel thrombosis, anticoagulation is widely used, although without any strong supporting evidence and further approaches, including immunosuppression, may be required.

This Task Force Report reviews and updates "APS Treatment Trends" that have been discussed during the 16th International Congress on aPL, convened in Manchester, United Kingdom, in September 2019. It represents a continuation of the work of the 14th and 15th International Congress on aPL Task Force Reports. 5,6

\section{Brief overview of the pathogenesis of antiphospholipid syndrome}

Evidence suggests that prothrombotic, proinflammatory and angiogenic pathways are involved in the pathogenesis of aPL-related thrombosis, in turn suggesting why antithrombotic treatment alone may not suffice. A key initiating pathogenic process in cell activation is binding of $\beta_{2}$ GPI to exposed, negatively charged phospholipids on the surface of endothelial cells, monocytes and platelets, which may all be involved through the shedding of prothrombotic microparticles. Cell activation likely involves binding of $\mathrm{a} \beta_{2} \mathrm{GPI} /$ $\beta_{2}$ GPI complexes to toll-like receptor 4 (TLR4), annexin A2 or low density lipoprotein receptorrelated protein 8 (LRP8) and activation of their intracellular signal transduction pathway, with induction of $\mathrm{P} 38 /$ mitogen-activated protein kinase (P38/MAPK) and nuclear factor kappa-B (NFkB)-dependent genes, resulting in a prothrombotic and proinflammatory phenotype. ${ }^{7}$ Expression of tissue factor (TF), a key initiator of in vivo coagulation, and vascular endothelial growth factor are elevated in patients with aPL. ${ }^{8-10}$ Thrombotic APS patients have raised levels of complement activation markers ${ }^{11,12}$ and they are recognized as amplifiers of the inflammatory milieu. Increasing evidence suggests that aPL-related thrombosis is mediated by neutrophil activation, leading to release of extracellular chromatin-based structures, termed neutrophil extracellular traps (NETs) through a process known as NETosis. ${ }^{13}$ The key cellular and humoral molecular interactions of aPL leading to thrombosis can be both precipitated by (the "two-hit" hypothesis) and propagate inflammation. ${ }^{14}$

\section{Direct oral anticoagulants (DOACs)}

Vitamin K antagonists (VKAs), notably warfarin, are the standard treatment for thrombotic APS. ${ }^{5,6,15,16}$ The primacy of VKAs for the anticoagulation of APS patients has been challenged by the introduction of direct oral anticoagulants (DOACs). The advantages of DOACs compared to warfarin include prescription of a fixed dose with predictable anticoagulant effect and no routine anticoagulation monitoring, having fewer drug interactions, and no alimentary interactions. These characteristics are appealing for thrombotic APS patients who generally require life-long anticoagulation.

\section{Randomized controlled trial (RCT) evidence}

RAPS: Rivaroxaban in antiphospholipid syndrome. This phase $2 / 3$ randomised controlled trial (RCT) compared rivaroxaban $20 \mathrm{mg}$ once daily versus standard-intensity warfarin, target INR 2.5 (range 2.0-3.0) in 116 patients with a first episode of venous thromboembolism (VTE), or recurrence while on subtherapeutic or no anticoagulation. Twenty-eight percent of patients overall $(24.6 \%[14 / 57]$ on rivaroxaban, $32.2 \%$ [19/59] on warfarin) were triple-positive for $\mathrm{aPL}$, i.e. LA, aCL $\mathrm{IgG} / \mathrm{M}$, and $\mathrm{a} \beta_{2}$ GPI $\mathrm{IgG} / \mathrm{M}$. Patients with previous APS-related arterial thrombosis were excluded. The primary outcome, percentage change in endogenous 
thrombin potential (ETP) for rivaroxaban, did not reach the non-inferiority threshold. However, peak thrombin was significantly lower on rivaroxaban versus warfarin and the authors concluded that the overall thrombin generation curve, in which the higher ETP reflects the altered reaction kinetics with rivaroxaban, was not indicative of increased thrombotic risk. Although the trial was not powered for clinical outcomes, there were no thrombotic events during seven months of follow-up. ${ }^{17}$

TRAPS: Rivaroxaban in thrombotic APS. This phase 3 RCT designed to enroll 536 patients compared rivaroxaban $20 \mathrm{mg}$ once daily (or $15 \mathrm{mg}$ once daily if renally impaired [2/59 patients]) versus warfarin target INR 2.5 , and recruited 120 triple aPL-positive thrombotic APS patients. This trial was terminated prematurely at the recommendation of the safety committee after a mean follow-up of 1.6 years. Thromboembolic events occurred in seven of 59 patients (annualised thrombosis rate $7.5 \%$ ) randomised to rivaroxaban (four ischemic strokes and three myocardial infarctions), compared to none on warfarin. Nineteen percent $(11 / 59)$ of patients on rivaroxaban had previous arterial thrombosis and comprised $57 \%(4 / 7)$ of those with recurrent thrombosis. $^{18}$

Rivaroxaban versus VKA in APS: a noninferiority trial. This phase 3 trial randomised 190 patients with thrombotic APS, approximately $60 \%$ triple aPL-positive, to rivaroxaban $20 \mathrm{mg}$ once daily (or $15 \mathrm{mg}$ once daily if renally impaired [5/95 patients]) versus VKA, target INR 2.03.0 (or target INR 3.1-4.0 among those with a history of recurrent thrombosis). The annualised recurrent thrombosis rate after three years follow-up was $3.9 \%$ on rivaroxaban versus $2.1 \%$ in the VKA group. Stroke occurred more commonly in patients receiving rivaroxaban (nine events) than in those receiving VKA (0 events) (corrected relative risk (RR), 19.00 [confidence interval (CI), 1.12 to 321.9]). Post hoc analysis suggested an increased risk of recurrent thrombosis in rivaroxaban-treated patients with previous arterial thrombosis, livedo racemosa, or APS-related cardiac valvular disease. ${ }^{19}$

ASTRO-APS: Apixaban for the secondary prevention of thrombosis in APS. The ASTRO-APS trial protocol (apixaban $2.5 \mathrm{mg}$ twice daily versus warfarin INR 2.0-3.0 in thrombotic APS patients ${ }^{20}$ [ClinicalTrials. gov Identifier: NCT02295475]) was modified twice due to a higher rate of thrombosis in patients with a history of arterial thrombosis. The protocol was modified after recruitment of 25 patients, to use apixaban $5 \mathrm{mg}$ twice daily instead of $2.5 \mathrm{mg}$ twice daily. Subsequently, five patients were enrolled. Because of investigator concern for a possibly higher rate of stroke among patients randomized to apixaban, a second protocol modification excluded the subsequent enrollment of APS patients with prior arterial thrombosis, and required MRI of the brain prior to randomization. $^{21}$ Patient enrollment and follow-up is now complete and the investigators hope to publish results in 2020 .

\section{Other evidence}

A phase 4 pilot study of rivaroxaban $20 \mathrm{mg}$ daily was completed in 82 APS patients with prior VTE. The authors reported recurrent thrombosis in $4.9 \%$ $(n=4)^{22}$ and concluded that the rate of recurrent thrombosis after at least a year of follow-up was comparable to previous RCTs (annualised recurrent thrombosis rate $1.3-4 \%)^{23,24}$ among thrombotic APS patients treated with warfarin. A prospective cohort study of 176 patients with 51 months follow-up (82 on DOACs [42 on apixaban, 36 on rivaroxaban and 4 on dabigatran] and 94 on VKA) reported annualized recurrent thrombosis rates of $3.3 \%$ (3/10 arterial) and 2.5\% (2/12 arterial) for DOACs and warfarin, respectively. ${ }^{25} \mathrm{~A}$ retrospective case control study including 18 patients on DOACs (12 on edoxaban, 5 on rivaroxaban and 1 on apixaban) and 36 matched controls on VKA followed for 5 years reported annualized recurrent thrombosis rates of $6.6 \%$ for DOACs and $4.4 \%$ for VKA. ${ }^{26}$

A systematic review of 728 APS patients on DOACs (48\% triple aPL-positive) reported an annualised recurrent thrombosis rate of $11 \%$. Factors associated with a higher risk for recurrent thrombosis included a higher mean number of prior thrombotic events, a history of combined arterial and venous thrombosis, previous treatment with low-molecular-weight heparin (LMWH), use of immunosuppressant treatment, and patient preference to switch to a DOAC. ${ }^{27}$ An earlier individual patient data meta-analysis of 447 patients, in which the annualised recurrent thrombosis rate was $11.7 \%$, suggested that additional risk factors for recurrent thrombosis include triple aPL-positivity, a higher number of clinical criteria for APS classification, prior thrombosis while on a VKA and, in patients treated with anti-Xa inhibitors, a history of arterial or small vessel thrombosis. Among the $73 / 447$ patients with recurrent thrombosis, 31 had arterial events; 18 $(58 \%)$ of these had a prior single VTE, with $10 / 18$ $(56 \%)$ triple aPL-positive. ${ }^{28}$

\section{DOACs and VTE among patients with APS}

DOACs are established as standard treatment for 'general population' patients with a first unprovoked VTE following large phase 3 multicentre international RCTs 
of DOACs versus standard-intensity warfarin. ${ }^{29}$ These trials did not focus on APS patients, although post hoc analysis of the RE-COVER ${ }^{\circledR}$, RE-COVER II $^{\mathrm{TM}}$, and RE-MEDY ${ }^{\mathrm{TM}}$ RCTs indicated that the efficacy and safety of dabigatran etexilate were not significantly different among patients with at least one positive criteria aPL test and VTE. ${ }^{30}$ A prospective cohort study in 290 patients with a first unprovoked VTE found that $9 \%$ met criteria for APS, showing persistent aPL. Two patients, i.e., $1 \%$ of the 191 patients tested for all three aPL, were triple aPL-positive, with persistent triple aPL-positivity proven in one. ${ }^{31}$ A crosssectional study of 491 patients with a first unprovoked VTE also found that $9 \%(44 / 491)$ of patients met criteria for APS, with $1.4 \%$ (7/491) being persistently triple aPL-positive. ${ }^{32}$ These observations raise the issue of the optimal timing for aPL testing after a first VTE.

Testing for LA in the acute post-thrombotic state may be confounded by acute phase reactants such as factor VIII $^{33}$ and C-reactive protein, ${ }^{34}$ as well as the effects of anticoagulation treatment, ${ }^{35}$ as false positive and negative results can occur. In contrast, triple aPLpositivity persists in the majority of patients, ${ }^{36,37}$ although it occurs in only a minority of patients with a first VTE. ${ }^{31,32}$ Guidance regarding the timing of thrombophilia testing including testing for APS exists. ${ }^{38}$ It may be preferable to defer screening for aPL for most patients with a new VTE in the acute setting. For those patients in whom there is clinical concern for APS, however (e.g., patients with a new VTE and obstetric or non-criteria manifestations of APS), testing can be performed with appropriate interpretation of the laboratory results.

\section{DOACs and APS-related stroke}

Standard dosages of DOACs have been established to be effective versus standard-intensity warfarin as the comparator following a first VTE episode in 'general population' patients. ${ }^{29}$ However, whether standard doses of DOACs offer sufficient protection against recurrent thrombosis when high intensity anticoagulation is recommended is an uncertainty. ${ }^{16,39}$ There is a lack of consensus regarding appropriate VKA anticoagulation intensity for APS patients in certain circumstances which reflects the lack of conclusive data. The European League against Rheumatism (EULAR) guidelines, based on pooled data from two retrospective studies and two RCTs showing no significant difference in thrombosis recurrences between INR target 3.0-4.0 versus 2.0-3.0 (relative risk 0.46 [0.06-3.52]), recommend treatment with VKA with INR 2.0-3.0 or
INR 3.0-4.0 in APS patients with a first arterial thrombosis, considering the individual's risk of bleeding. ${ }^{16,40}$ The RISAPS RCT aims to investigate the use of highintensity rivaroxaban $15 \mathrm{mg}$ twice daily versus warfarin in APS patients with stroke or other ischaemic brain manifestations: (ClinicalTrials.gov Identifier: NCT03684564).

\section{Other considerations regarding DOAC use in APS}

The role of DOACs in APS is not established, and APS, by definition a syndrome, includes a population that is heterogenous in clinical and laboratory manifestations of disease. The TRAPS trial ${ }^{18}$ triggered the risk assessment that led to the European Medicines Agency (EMA) statement that DOACs are not recommended for thrombotic APS patients, especially those who are triple positive for aPL. The United States Food and Drug Administration (FDA) has endorsed the EMA recommendations, ${ }^{41}$ as have other regulatory authorities worldwide. Of note, DOACs are not contraindicated for APS. ${ }^{42-45}$ The TRAPS trial included only triple aPL positive patients, whereas the EMA recommendation extends to all APS patients. Definitive evidence regarding the role of DOAC therapy among patients with thrombotic APS is required. However, concern remains that guidance from regulatory bodies, such as that noted above, will diminish clinician drive and patient willingness to participate in clinical studies necessary to inform optimal care.

\section{Task force recommendations}

\section{Recommendations for clinicians.}

1. DOACs should be avoided in APS patients with arterial thrombosis. For these patients, first line therapy should be a VKA.

2. DOACs should be avoided in thrombotic APS patients with small vessel thrombosis or aPL-related cardiac valvular disease. The first line anticoagulant option should be a VKA.

3. For patients found to have single- or double-positive aPL following a first episode of VTE (in the acute setting or later in their course), we suggest that continuation of the DOAC may be considered, while awaiting confirmation of persistence of aPL, based on testing after at least 12 weeks, and thereafter. Discussion with the patient and shared decisionmaking regarding the the perceived risks, benefits, and the uncertainties of choice of anticoagulant should be undertaken. Testing for a 32 GPI to distinguish patients with double- rather than triple aPLpositivity should be performed if a DOAC is considered. 
4. For triple aPL-positive APS patients, if started on a DOAC upon initial presentation with a first episode of VTE, and upon considering limitations of testing (especially as it pertains to assessment for the presence of LA), we recommend that therapy be switched to warfarin or an alternative VKA. If the patient declines, then the DOAC may be continued, with clinical surveillance. It is suggested that surveillance could include MRI brain imaging to identify ischaemic lesions, which, if present, merit consideration of a switch to alternative anticoagulation, with the first option a VKA.

5. DOACs should not be used in APS patients with recurrent thrombosis while on standard-intensity VKA. Other treatment options may include an increased target INR range, standard treatment dose low-molecular-weight heparin (LMWH), fondaparinux if VKA/LMWH are not suitable, or the addition of antiplatelet therapy.

\section{Clinical research agenda.}

1. Further studies are required to determine the potential role of DOACs in thrombotic APS. These studies need to take into account that APS is heterogeneous and that thrombotic risk is influenced by both the clinical and laboratory APS phenotype.

2. All cases of DOAC use in APS patients should be reported to the International Society on Thrombosis and Haemostasis-supported international registry, currently being established (ClinicalTrials.gov Identifier: NCT04262492). This Registry will ensure consistency of data collection and provide safety information in APS patients currently on DOACs.

\section{Antiplatelet agents}

\section{Low dose aspirin}

Aspirin irreversibly inhibits the cyclooxygenase activity of prostaglandin $\mathrm{H}$ synthase-1 in platelets, thereby blocking the formation of thromboxane A2, which is a potent vasoconstrictor and facilitates platelet aggregation. Low dose aspirin (LDA), in combination with prophylactic dose LMWH, is standard treatment during pregnancy for obstetric APS. ${ }^{15,16,46}$ A metaanalysis of five trials involving 334 patients with recurrent miscarriage, reported live birth rates of $74.3 \%$ and $55.9 \%$ in women who received a combination of unfractionated heparin/LMWH plus LDA or LDA alone, respectively. ${ }^{47}$ The role of LDA for primary prevention of thrombosis in non-pregnant women with a history of obstetric APS and individuals with persistent aPL is considered below.

\section{Low dose aspirin for primary prevention of thrombosis in patients with persistent antiphospholipid antibodies}

A meta-analysis of 10 observational studies, and one RCT (1208 patients and 139 thrombotic events), investigated the utility of LDA in aPL-positive individuals asymptomatic for thrombosis. The majority of the patients had double- or triple-aPL positivity, or persistently high aPL titres. Subgroup analysis showed that the risk of a first venous thromboembolic event (VTE) was significantly decreased by the use of LDA among asymptomatic aPL-positive individuals (7 observational studies; odds ratio (OR): 0.50 [0.25-0.99]); patients with SLE (7 observational studies, 1 RCT; OR: 0.55 [0.31-0.98]); or those with a history of obstetric APS (5 observational studies; OR: 0.25 [0.10-0.62]). ${ }^{48}$

An individual patient meta-analysis of five cohort studies by the same group included 497 subjects with 79 first thrombotic events. After adjustment of cardiovascular risk factors, aPL profiles, and treatment with hydroxychloroquine, a hazard ratio (HR) for the risk of a first thrombosis of any type in aPL carriers treated with LDA versus those not treated with aspirin was $0.43(95 \%$ CI $0.25-0.75)$. Subgroup analysis showed a protective effect of LDA against arterial (HR: 0.48 [95\% CI: $0.28-0.82]$ ) but not venous thrombosis as well as in retrospective (OR: 0.23 [0.13-0.42]) but not prospective studies (OR: 0.91 [0.52-1.59]. After further adjustment on the gender, age, and presence of cardiovascular risk factors, subgroup analysis showed a protective effect of aspirin against arterial thrombosis was observed in patients with SLE (HR: 0.43 [95\% CI: 0.20 0.93]) and asymptomatic aPL carriers (HR: 0.21 [95\% CI 0.04-0.99). The number of women with obstetric APS was relatively small, limiting conclusions: $15 / 221$ (7\%) of patients on LDA and 65/276 (24\%) of those not on LDA. ${ }^{49}$ The APLASA (Antiphospholipid Antibody Acetylsalicylic Acid) trial was the only RCT that directly addressed the question of the efficacy of LDA in primary thrombosis prevention in asymptomatic, persistently aPL-positive individuals, but could not confirm the benefit of low dose aspirin for primary prophylaxis in this setting, perhaps due to limited power and/or sample size. ${ }^{50}$ Of note, a prospective study reported a significantly increased rate of VTE and cerebrovascular events, in women with obstetric APS, despite low-dose aspirin primary prophylaxis, compared to women with heritable thrombophilia or with negative thrombophilia screens. ${ }^{51}$ 
It is unclear whether the benefit of LDA outweighs the risk of major bleeding associated with LDA in a low-risk population. The estimated average annual incidence rate of overall VTE in the general population is $0.1-0.18$ per 100 patient-years and similar to that of stroke. ${ }^{52}$ The annual incidence of thrombosis in unselected aPL-positive patients is reported to be 0 to $2.8 \%{ }^{53} \mathrm{~A}$ more recent review estimated that the annual thrombosis rate among aPL-positive individuals with or without systemic autoimmune disease (SAID) is 0 to $5.3 \%$, probably very low $(<1 \% /$ year $)$ in those with no other SAID or other thrombosis risk factors. The authors suggest risk stratification, based on aPL profile, age, additional SAIDs and traditional cardiovascular or VTE risk factors. ${ }^{54}$ Compared with the general (non-aspirin treated) population, the risk of major bleeding with LDA for primary cardiovascular disease prevention was reported in a systematic review to be 3.6 per 1000 person-years. ${ }^{55}$ This systematic review reported that LDA increased major gastrointestinal bleeding risk by $58 \%$ (OR, 1.58 [95\% CI, 1.29 to 1.95]) and haemorrhagic stroke risk by $27 \%$ (OR, 1.27 [CI, 0.96 to 1.68$]) .{ }^{55}$ SLE is associated with increased thrombotic risk, (both arterial and venous), increased by the presence of aPL. ${ }^{56}$ In the absence of RCTs evaluating prophylactic strategies, recommendations are based on analysis of lower quality studies and expert opinion.

The EULAR guidelines advise that the decision to treat with LDA for primary thromboprophylaxis should be based on stratification of thrombotic risk: ${ }^{16}$ thus, in asymptomatic aPL carriers, with a 'high-risk' aPL profile (defined as the presence of persistent LA, double- or triple-aPL positivity, or persistently high aPL titres) with or without traditional risk factors and in patients with SLE and a 'high-risk' aPL profile, prophylactic treatment with LDA is recommended (2a/B). In individuals with a 'low-risk' aPL profile (defined as isolated aCL or a $\beta_{2}$ GPI at low-medium titres, particularly if transiently positive), the EULAR guidelines advise that LDA may be considered $(2 \mathrm{~b} / \mathrm{C})$. They advise that non-pregnant women with a history of obstetric APS (with or without SLE) as the sole manifestation of APS should receive prophylactic treatment with LDA, after adequate risk/benefit evaluation $(2 \mathrm{a} / \mathrm{B}) \cdot{ }^{16,40}$

\section{Low dose aspirin for secondary prevention of thrombosis}

Optimal antithrombotic therapy among APS patients with prior stroke/transient ischaemic attack remains uncertain. Prospective evidence has suggested that no substantive benefit exists between high-intensity and standard-intensity warfarin, although patients with arterial thrombosis were under-represented. ${ }^{23,24}$ Small prospective cohort evidence suggests VKA over LDA for APS-related stroke. ${ }^{57}$ The APASS (Antiphospholipid Antibodies and Stroke Study) in older patients with stroke reported no difference in event recurrences between LDA and warfarin, ${ }^{58}$ but aPL testing did not fulfil the international APS laboratory classification criteria. ${ }^{1}$ While no definitive data exist, professional society guidance to elect either high-intensity VKA or standard-intensity VKA, with or without antiplatelet therapy has been recommended. ${ }^{16}$ Based mainly on expert consensus, the EULAR guidelines recommend consideration of LDA plus standard-intensity VKA $(4 / C)$ as an option, in addition to consideration of standardversus high-intensity VKA alone, following a first arterial thrombosis; and, in APS patients with recurrent arterial or venous thrombosis on standard-intensity VKA, addition of LDA, increase of INR target to $3.0-4.0$ or change to LMWH. ${ }^{16,40}$

There is a lack of data about the use of other antiplatelet agents in patients with aPL/thrombotic APS, including clopidogrel, prasugrel, ticagrelor and cangrelor. Dipyridamole, a phosphodiesterase inhibitor, that inhibits platelet function and induces vasodilation, ${ }^{59}$ also appears to inhibit aPL-mediated NETosis (discussed below).

\section{Recommendations for clinicians}

1. In asymptomatic aPL carriers, with or without SLE, or in individuals with prior obstetric APS, with persistent LA, double- or triple-aPL positivity, or persistently high aPL titre, LDA should be considered for primary prevention of thrombosis on a case-bycase basis.

2. In asymptomatic aPL carriers, with or without SLE, or in individuals with prior obstetric APS who have any other aPL laboratory phenotypes, LDA may be considered for primary prevention of thrombosis on a case-by-case basis.

3. The risk-benefit analysis should include patientrelated factors for arterial thrombosis and VTE. Risk factors for bleeding and upper gastrointestinal reflux disease should also be taken into account.

4. There is insufficient evidence to make strong recommendations about the use of LDA for secondary prevention following a first APS-associated arterial thrombosis. LDA may be considered, in combination with standard-intensity VKA (target INR 2.5, range 2.0-3.0), in APS patients with a first arterial thrombosis, with an alternative option high-intensity VKA.

5. LDA may be considered, in combination with anticoagulation, in APS patients who develop recurrent 
arterial or venous thrombosis while on standardintensity VKA.

\section{Clinical research agenda}

1. RCTs should be undertaken to define the potential role of LDA or other antiplatelet agents for primary prevention of thrombosis in aPL-positive patients asymptomatic for thrombosis.

2. RCTs are also required to define the role of LDA or other antiplatelet agents, in combination with anticoagulation, in thrombotic APS patients.

\section{Adjunctive therapies}

The majority of thrombotic APS patients respond to anticoagulation, but a small proportion continue having clinical events despite anticoagulation. Hydroxychloroquine, statins and vitamin D may have a role as adjunctive treatment in the treatment of thrombotic APS patients.

\section{Hydroxychloroquine}

In vitro and in vivo studies show that antithrombotic effects of hydroxychloroquine (HCQ), standard treatment in SLE, include reversal of aPL-induced platelet activation, ${ }^{60}$ reduction of LDL and VDRL cholesterol, and increased HDL cholesterol levels. ${ }^{61}$ HCQ also protects the annexin A5 anticoagulant shield from syncytiotrophoblast disruption by aPL. ${ }^{62}$ HCQ reduced clot formation and thrombin generation in a mouse model and in human endothelial cells. It may improve endothelial function and correct the proinflammatory phenotype observed both in vivo and in vitro. ${ }^{61}$ A retrospective study suggested that HCQ may also reduce aPL titres in primary APS patients. ${ }^{63}$ A prospective study showed that long-term HCQ use (average 2.6 years) was associated with a decrease in aPL titers. ${ }^{64}$

\section{Primary prevention of thrombosis}

HCQ has been related to a reduction in thrombosis risk in aPL-positive patients with SLE $^{65}$ although the aforementioned individual patient meta-analysis found no independent protective effect of hydroxychloroquine. $^{49}$ The Antiphospholipid Syndrome Alliance for Clinical Trials and International Networking (APS ACTION) initiated a multicentre, international RCT of HCQ versus standard care in persistently aPL-positive, thrombosis-free patients without systemic autoimmune diseases. The trial was terminated early due to the low recruitment rate $(n=20)$, exacerbated by the prolonged manufacturing shortage and significant price increase of HCQ in the United States.
Thus, no conclusions on the effectiveness of HCQ could be made. The authors concluded that conducting an international RCT without pharmaceutical industry support is extremely challenging. ${ }^{66}$

\section{Hydroxychloroquine: Secondary prevention of thrombosis}

Data on the role of HCQ in secondary prevention of thrombosis in primary APS patients are also scarce. A prospective non-randomised study in 40 patients suggested that adding HCQ to oral anticoagulation with VKA reduced VTE in patients with primary APS. ${ }^{67}$ The HIBISCUS project was proposed to study the use of HCQ in secondary prevention of thrombotic and obstetric events in primary APS. ${ }^{68}$ A prospective RCT of HCQ versus placebo aims to assess the role of HCQ in the secondary prevention of thrombotic events (ClinicalTrials.gov Identifier: NCT03540810).

\section{Hydroxychloroquine: Obstetric APS}

Standard treatment with LDA plus LMWH to improve obstetric outcome fails in $20-30 \%$ of APS patients. ${ }^{47} \mathrm{~A}$ systematic review analysed the limited evidence and found that one study showed that HCQ improved pregnancy outcome, but its effect was not adjusted for the use of other medications (LDA, LMWH, steroids). An expert panel concluded that HCQ use could be considered after failure of standard treatment and in women with previous thrombosis (either arterial and/or venous), and/or with previous ischaemic placentamediated complications. ${ }^{69}$ EULAR recommendations for the use of HCQ in pregnancy state that in women with 'criteria' obstetric APS with recurrent pregnancy complications despite combination treatment with LDA and heparin at prophylactic dosage, increase of heparin to therapeutic dose, addition of hydroxychloroquine or addition of low-dose prednisolone in the first trimester may be considered. ${ }^{16}$ In a retrospective cohort study of 170 pregnancies in 96 women, HCQ treatment was associated with a higher rate of live births $(67 \%$ in HCQ-treated vs $57 \%$ in those who did not receive hydroxychloroquine; $\mathrm{P}=0.05$ ) and a lower prevalence of aPL-related pregnancy morbidity $(47 \%$ vs $63 \%$ respectively; $\mathrm{P}=0.004) .{ }^{70} \mathrm{~A}$ multicentre $\mathrm{RCT}$ of HCQ versus placebo during pregnancy in women with aPL (HYPATIA; HYdroxychloroquine to Improve Pregnancy Outcome in Women with AnTIphospholipid Antibodies) is assessing the effect of HCQ on adverse pregnancy outcomes. ${ }^{71}$ A prospective RCT of HCQ versus placebo aims to assess the role of HCQ in achieving an uncomplicated term pregnancy in primary obstetric APS (ClinicalTrials.gov Identifier: NCT04275778). 


\section{Task force recommendations}

Recommendations for clinicians.

1. The addition of HCQ may be considered as adjunctive to antithrombotic treatment, for anticoagulantrefractory thrombotic APS, in accordance with our previous Task Force recommendations. ${ }^{5,6}$

2. The addition of HCQ to standard treatment may be considered in patients with obstetric APS refractory to standard treatment with LDA and LMWH.

\section{Clinical research agenda.}

1. The potential benefit of HCQ use in non-SLE patients with aPL/thrombotic APS should be explored further in appropriate studies.

2. The results of ongoing studies could inform HCQ use in primary APS.

\section{Statins}

Statins inhibit the enzyme HMG-CoA reductase which has a central role in hepatic cholesterol production, but also have pleiotropic effects including anti-inflammatory and antithrombotic actions on endothelial cells and monocytes. ${ }^{72}$

Statins: Primary prevention of thrombosis. Numerous studies in the general population show that statin use leads to primary ${ }^{73}$ and secondary ${ }^{74}$ prevention of cardiovascular disease, and statins have been reported to reduce the occurrence of symptomatic VTE among healthy individuals. ${ }^{75}$ However, we are not aware of published studies on the use of statins for primary or secondary prevention of thrombosis in aPL-positive patients. Statins reduce aPL-induced expression of TF and cell adhesion molecules. ${ }^{76,77}$ A prospective, open label pilot study concluded that the use of fluvastatin in aPLpositive patients, reduced proinflammatory and prothrombotic biomarkers such as interleukin (IL)-6, IL1 $\beta$, vascular endothelial growth factor, TNF- $\alpha$, interferon- $\alpha$ and soluble tissue factor. ${ }^{78}$

Statins: Secondary prevention of thrombosis. There is no evidence supporting statin use in APS patients with normal lipid levels, as also concluded in our previous Task Force reports. ${ }^{5,6}$ The importance of hyperlipidaemia for thrombosis prediction in APS patients is emphasised by its inclusion, together with hypertension and aPL status, in the Global AntiphosPholipid Syndrome Score (GAPSS), a well-known, validated score in APS. ${ }^{79}$ The adjusted GAPSS has been applied to asses the risk of recurrent thrombosis in the APS ACTION cohort and for risk stratification in young APS patients with acute myocardial infarction. ${ }^{80,81}$
Statins: Obstetric APS. The global prevalence of preeclampsia, a leading cause of maternal and fetal mortality, is estimated to be $4.6 \%$ (95\% CI $2.7 \%-8.2 \%)$ of primigravidae. ${ }^{82}$ Studies in animal models and in humans suggest that pravastatin may prevent pregnancy complications associated with placental dysfunction, particularly preeclampsia. ${ }^{83}$ A large cohort study showed that statins in the first trimester do not appear to be associated with congenital fetal abnormalities. ${ }^{84}$ In this regard, pravastatin is hydrophilic and may have a limited passage through the placenta. ${ }^{83} \mathrm{~A}$ small open label non-randomized study investigated the effect of pravastatin $20 \mathrm{mg}$ od in 21 pregnant women with probable APS with early severe preeclampsia and/or fetal growth restriction (FGR). All women received treatment with LDA plus LMWH and $11 / 21$ received additional pravastatin $(20 \mathrm{mg} / \mathrm{d})$. Results suggested that pravastatin improves pregnancy outcomes in women with refractory obstetric APS when taken at the onset of preeclampsia or FGR until the end of pregnancy. ${ }^{85}$ However, a randomised, double-blind, placebo-controlled trial in 62 women with early-onset severe pre-eclampsia (without APS) showed no improvement in pregnancy outcome with pravastatin $40 \mathrm{mg}$ daily. ${ }^{86}$

A systematic review that included 16 clinical studies, noted that although early uncontrolled case series reported congenital anomalies associated with statin use, more recent observational studies did not report an increased risk of congenital anomalies with statin exposure in pregnancy when compared to control groups or the prevalence of congenital anomalies in the non-APS pregnant population. The findings of this systematic review showed no clear relationship of congenital anomalies with statin use in pregnancy, and supported the conclusion that statins are probably not teratogenic. ${ }^{87}$ The United States FDA and other parts of the world still categorise statins as contraindicated in pregnancy, which limits their application during pregnancy.

\section{Task force recommendations}

\section{Recommendations for clinicians.}

1. Statins may be beneficial in the primary and secondary prevention of arterial thrombosis in patients with aPL/APS. However, based on available data, statins cannot be recommended in patients with aPL/APS in the absence of hyperlipidaemia, in accordance with general population guidelines

2. Statins may be considered as adjunctive to antithrombotic treatment in anticoagulant-refractory thrombotic APS patients. 
These recommendations accord with our previous Task Force reports. 5,6

\section{Clinical research agenda.}

1. There is a pressing need for further studies on statins, to define clinical and laboratory indications/ biomarkers to inform RCTs in individuals with aPL/thrombotic APS.

2. Studies should be performed to define the potential utility of statins in patients with thrombotic APS.

3. The results of active largescale RCTs investigating whether statins can improve pregnancy outcomes in women at high risk of pre-eclampsia, should guide the future use of statins during pregnancy.

Vitamin D. Low vitamin D levels correlate with venous and arterial thrombotic manifestations in APS patients. Vitamin D insufficiency $(<30 \mathrm{ng} / \mathrm{mL})$ occurs in up to $70 \%$ of APS patients, while the prevalence of vitamin $\mathrm{D}$ deficiency $(<10 \mathrm{ng} / \mathrm{mL})$ ranges between $11-50 \%{ }^{88-90}$ Notably, not only were vitamin D levels shown to be lower in APS patients compared to controls, but values in APS patients with thrombotic manifestations were significantly lower than in APS patients with only obstetric manifestations. ${ }^{89,90}$ A retrospective cohort study and meta-analysis of four case-control studies confirmed that the combined mean difference in serum vitamin D levels between APS and controls was $-3.605(\mathrm{p}<0.001)$ and that APS patients had an approximately 3-times increased frequency of vitamin $\mathrm{D}$ deficiency. ${ }^{91}$ These studies suggest a possible role of vitamin $\mathrm{D}$ in ameliorating the development of thrombotic complications in aPL-positive individuals.

The central role of inflammation in aPL-mediated thrombosis underpins the potential of vitamin $\mathrm{D}$ in treating APS patients since it possesses numerous immunomodulatory properties. ${ }^{92}$ Among its many effects, the ability of vitamin D to inhibit TLR4/ MyD88 signaling, ${ }^{93,94}$ TF expression ${ }^{88}$ endothelial activation, and inflammation and cell perturbation play crucial roles in obstetric as well as thrombotic APS ${ }^{95,96}$ An in-vitro study demonstrated that vitamin D modulates signalling through TF/PAR-2, indicating that it could potentially limit TF/PAR-2 mediated placental inflammation and subsequent adverse outcomes in APS pregnancies. ${ }^{97}$ Studies evaluating pravastatin provide further evidence for vitamin D treatment in obstetric APS since this drug has been shown to prevent adverse pregnancy outcomes in APS patients and mouse models. Pravastatin blocks TF and PAR2 expression on neutrophils and increases vitamin D levels in animal models, ${ }^{84,98}$ suggesting that these effects could underlie its potential efficacy in treating pregnant patients with APS. In the early stages of pregnancy, trophoblasts respond to and produce vitamin $\mathrm{D}$, which promotes an anti-inflammatory environment and induces decidualization for successful obstetric outcomes. ${ }^{99,100}$ In the general population, vitamin D deficiency in pregnant women is associated with an increased risk of obstetric complications including pre-eclampsia and fetal growth restriction. ${ }^{101}$ A retrospective cross-sectional study of women with recurrent pregnancy losses highlighted an association between the presence of aPL and low vitamin D levels. ${ }^{102}$ Low vitamin D levels were associated with complement activation, placental insufficiency and pre-eclampsia in this study.

In a small observational study evaluating vitamin D deficiency in primary APS patients, vitamin D supplementation in a subgroup of these patients (average $400 \mathrm{IU}$ daily) was ineffective in raising levels above $30 \mathrm{ng} / \mathrm{mL}$ in approximately $60 \%$ of patients. ${ }^{90}$ In contrast, a more recent interventional study of 16 APS patients receiving supplementation with $1000 \mathrm{IU}$ vitamin D daily for 3 months reported an almost doubling of median 25-hydroxy vitamin D3 levels. ${ }^{103}$ Interventional studies of vitamin D supplementation in the general population and in other chronic prothrombotic conditions have utilized doses as high as 100,000 IU monthly, although the antithrombotic effect of vitamin D treatment in these studies was not conclusively demonstrated. ${ }^{104}$

\section{Task force recommendations}

\section{Recommendations for clinicians.}

1. Vitamin D deficiency and insufficiency should be corrected in all aPL-positive patients based on the general population guidelines, as also recommended in our previous Task Force reports. 5,6

\section{Clinical research agenda.}

1. The prognostic role of vitamin D deficiency and therapeutic value of supplementation (including the dosage and definition of treatment goals) in aPLpositive patients should be clarified with prospective studies that include appropriate control groups and standardized definitions of vitamin D deficiency.

2. In addition to clarifying the role of vitamin D treatment in ameliorating thrombotic and obstetric pathology in APS amid dosage considerations, further studies are needed to determine if vitamin D deficiency observed in APS patients occurs as a part of disease pathogenesis, and/or a consequence of disease activity and/or an incidental disease modifying factor. 


\section{Biologics: Rituximab, belimumab, and anti-TNF therapies}

Autoantibodies have a central role in the pathogenesis of APS, ${ }^{105}$ thus, B-cells are a potential therapeutic target. Currently, belimumab and rituximab are the two most commonly used B-cell modulating agents in the treatment of autoimmune diseases.

\section{Rituximab}

Rituximab is a chimeric monoclonal antibody that blocks the CD20 molecule on many B-cell precursors and is currently approved in several countries for the treatment of rheumatoid arthritis and anti-neutrophil cytoplasmic antibodies (ANCA) vasculitis. Clinical trials in lupus failed to reach their primary endpoints, ${ }^{106,107}$ though rituximab is widely used in clinical practice and has been recommended in the guidelines of the American College of Rheumatology (ACR) ${ }^{108}$ and EULAR $^{109}$ for the treatment of lupus nephritis and by NHS England for more general use in lupus. ${ }^{110}$

The evidence for the use of rituximab in APS derives from multiple case reports, case series and an open label clinical trial. However, reports of its use for recurrent thrombosis are scarce. The largest reported case series includes five patients with SLE/APS patients who had recurrent thrombosis despite appropriate anticoagulation with warfarin. Four of these patients had no further thrombotic events after its use. ${ }^{111}$ In primary APS, only sporadic reports of successful treatment for thrombotic events are available. ${ }^{112,113}$ The data seem to be more promising for some non-criteria manifestations. An open-label phase II study of rituximab for non-criteria manifestations of APS demonstrated that the safety profile of rituximab in the disease was very similar to that reported in other autoimmune diseases. More than half $(13 / 19)$ of the patients enrolled had partial or complete response in treating aPL-related thrombocytopenia, cognitive dysfunction, aPL-related nephropathy or skin ulcers, despite no substantial change in aPL profiles. ${ }^{114}$ In contrast, a small observational study showed significant reductions of aCL levels in seven SLE patients (mean baseline IgG aCL level: 20.6 standardized IgG antiphospholipid units (GPLU) (range (SD) 10-32, (10.1), normal level <5) at 6-9 months post B-cell depletion with rituximab. ${ }^{115}$ Numerous cases have been reported describing the successful use of rituximab, in particular, for thrombocytopenia ${ }^{116}$ and skin ulcers. ${ }^{117}$ A growing number of case reports and series report on the use of rituximab for diffuse alveolar hemorrhage. Approximately 13 cases have been reported, with $50 \%$ of patients achieving remission using rituximab monotherapy or in combination with cyclophosphamide or mycophenolate mofetil. ${ }^{118-121}$
Rituximab has been reported in the treatment of CAPS. Based on the CAPS international registry, its use has been proposed for those patients who have had CAPS refractory to triple therapy (steroids, anticoagulation and plasma exchange). ${ }^{122-124}$ Finally, for obstetric manifestations of the disease, there is one case report of unsuccessful treatment in SLE/APS. ${ }^{125}$ The main caveat about the evidence available is that is predominantly based on case reports or series. This type of evidence is often biased as unsuccessfully treated patients are less frequently reported.

\section{Belimumab}

Belimumab is a monoclonal antibody directed against BAFF, a B cell activating molecule. ${ }^{126}$ This drug has been approved for use in SLE in several parts of the world. Several reports have shown that aPL titers in SLE patients treated with belimumab decrease. This effect was observed for both aCL and $a \beta_{2}$ GPI, but no change in LA status was noted. ${ }^{127,128} \mathrm{~A}$ post-hoc analysis of two randomised placebo-controlled trials in SLE did not show any significant effect of belimumab on IgG or IgM aCL titres, but only on IgA, notably in patients on concomitant antimalarials: median titre (interquartile range [IQR]) IgA aCL at baseline; placebo 22 (18; 30); belimumab $10 \mathrm{mg} / \mathrm{kg} 24$ (19; 37); median change [IQR] at 12 months: placebo $-7(-12$; 2); belimumab $10 \mathrm{mg} / \mathrm{kg}$ : $-10(-15 ;-7), \mathrm{p}<0.0007 .{ }^{129}$ Only two APS cases with clinical outcomes have been published; one with refractory lower extremity skin ulcers and one with thrombocytopenia. Both had a partial response and were able to taper glucocorticoids after the introduction of belimumab to the therapeutic regimen. ${ }^{130}$

\section{Anti-TNF therapy}

The PROMISSE (Predictors of Pregnancy Outcome: Biomarkers in Antiphospholipid Antibody Syndrome and Systemic Lupus Erythematosus), a longitudinal, prospective, multicenter observational study that enrolled pregnant women with aPL/APS and SLE (ClinicalTrials.gov Identifier: NCT00198068), has led to new insights about the role of TNF- $\alpha$ in pregnancy morbidity. In the PROMISSE study, $39 \%$ of pregnancies in women with APS and LA resulted in adverse pregnancy outcomes (APO) despite treatment with LMWH/unfractionated heparin and LDA. ${ }^{131}$ Angiogenic dysregulation early in pregnancy predicted $\mathrm{APO}$, most of which were due to failure of adequate vascularization of the developing placenta and underperfusion of the fetus. ${ }^{132}$ Mouse models show that aPL causes elevation of TNF- $\alpha$ levels in the placental tissues, that TNF- $\alpha$ levels are associated with pregnancy 
loss, and its blockade rescues pregnancies. ${ }^{133}$ In a recent case series, 18 aPL-positive women with obstetric APS refractory to LMWH, aspirin and hydroxychloroquine were treated with adalimumab or certolizumab. Seventy percent of the patients had a live birth. ${ }^{134}$ Currently the IMProve Pregnancy in APS with Certolizumab Therapy (IMPACT: ClinicalTrials.gov Identifier: NCT031 52058) clinical trial is ongoing in patients with obstetric APS. This trial should clarify the role of anti-TNF therapy for this APS manifestation. It is important to note that there are reported cases of the development ${ }^{135,136}$ or exacerbation ${ }^{137}$ of APS while using anti TNF therapy. These drugs currently have no role in other disease manifestations and may have deleterious effects. ${ }^{138}$

\section{Task force recommendations}

\section{Recommendations for clinicians.}

1. Rituximab may have a role in the treatment of some aPL-related non-criteria manifestations, such as thrombocytopenia, diffuse alveolar hemorrhage, aPL-related nephropathy and microvascular skin ulcers. Rituximab may also have a role in refractory CAPS. There is a paucity of evidence to inform the use of rituximab for anticoagulant-refractory thrombotic APS.

2. There are limited data currently, to support the use of belimumab in APS.

\section{Clinical research agenda.}

1. The introduction of fully humanised anti-CD20 monoclonals, e.g. obinutuzumab, offers the chance to undertake larger studies, without the relatively frequent allergic responses that accompany the use of rituximab. ${ }^{139}$

2. As belimumab becomes more widely available internationally, it should become easier to assess its true potential in both the thrombotic and non-criteria APS manifestations.

3. The results of the ongoing clinical trials using TNF$\alpha$ blockade might provide justification for its use in obstetric APS.

\section{Complement inhibition}

Complement activation contributes to thrombosis and pregnancy complications in animal models of APS. ${ }^{140,141}$ Extensive evidence indicates that aPL triggers complement activation (generation of $\mathrm{C} 5 \mathrm{a}$ ) and that specific complement inhibition (anti-C5a) reduces fetal loss. ${ }^{141}$ Inhibition of complement has also proven to be an effective therapeutic intervention for treating microvascular, as well as large vessel, thrombotic disease in paroxysmal nocturnal haemoglobinuria. ${ }^{142}$
Passive transfer of human aPL induced complement activation in pregnancy animal models. ${ }^{141} \mathrm{C} 5 \mathrm{a}$, a potent anaphylotoxin and chemotactic protein, promotes vascular inflammation and thrombosis by activation of inflammatory cells, endothelial cells and platelets. ${ }^{141,143}$ The inflammatory and prothrombotic milieu is amplified by C5a-C5aR interaction with increased recruitment of neutrophils and monocytes, expression of adhesion molecules and tissue factor by neutrophils, resulting in trophoblast damage and angiogenic factor imbalance. ${ }^{144,145}$ The importance of $\mathrm{C} 5 \mathrm{a}$ and $\mathrm{C} 5 \mathrm{aR}$ in rescuing aPL-mediated thrombosis phenotype has been confirmed in experimental models: C5a monoclonal antibodies (mAb), C5aR antagonist peptides and anti-C5aR mAb have been able to reverse the pathogenic effect of complement-induced fetal injury. ${ }^{146}$

Heparin, an anticoagulant used to treat thrombotic events and to prevent miscarriages, has been successfully used as an anti-inflammatory drug due to its anticomplement properties. ${ }^{147}$ Although complement has several implications in microvascular thrombotic diseases, few studies have demonstrated complement consumption in APS. One possible explanation is that complement activation products are unstable in vitro leading to collection artifacts and methodologic issues. Another possibility is that complement activation is local and not detectable in the circulation. Blood cell bound $\mathrm{C} 4 \mathrm{~d}$ has been reported to be a more sensitive indicator of complement activation in SLE and APS than serum levels of complement $\mathrm{C} 3$ and $\mathrm{C} 4 .{ }^{148} \mathrm{~A}$ novel 2-stage approach to measure aPL-induced complement components has proven to be more sensitive means of detection than traditional methods. When patient's plasma was preincubated with phospholipid vesicles. C5a and soluble C5b-9 levels were significantly increased in APS patients compared to controls. ${ }^{149}$ Further validation of these methodologies should be explored in larger prospective aPL/APS cohorts.

Outcomes in complement-mediated thrombotic microangiopathies (TMAs), such as paroxsysmal nocturnal hemoglobinuria (PNH) and atypical haemolytic uremic syndrome (aHUS), were improved with anticomplement therapy (anti-C5). Eculizumab, a monoclonal anti-C5 drug, has been utilised as salvage therapy in refractory CAPS in case reports. ${ }^{150-157}$ A recent study showed that CAPS patients experience a higher frequency of rare germline mutations of complement regulatory proteins, that might make them more susceptible to thrombosis. ${ }^{158}$ There is a substantial body of literature endorsing the use of eculizumab for preventing aPL-related nephropathy recurrence following renal transplantation. Eculizumab improved creatinine levels after infusion in three patients but failed to prevent chronic vascular changes, suggesting 
multiple mediators of disease pathogenesis. ${ }^{153}$ Anti$\beta_{2}$ GPI IgA levels appear to be an independent risk factors for early graft loss after renal transplantation in a retrospective cohort in Spain, but complement activation mediated by IgA needs evaluation. ${ }^{159}$ An association between complement activation and recurrent thrombosis in APS patients has been demonstrated using a functional modified HAM (mHAM) assay and patient-derived a $\beta_{2}$ GPI also increased C5b-9 deposition on the cell surface. These observations suggest a basis for the use of complement inhibition in patients with refractory thrombotic APS. ${ }^{158}$

The successful use of Eculizumab was reported in pregnancy, in a triple-positive APS patient with previous recurrent arterial events despite anticoagulation. ${ }^{160}$ Of note, an in vitro assay for eculizumab/C5 complexes demonstrated negligible drug concentration in the infant's serum. Results from the PROMISSE Study demonstrated that the $20.5 \%$ of SLE patients and/or aPL with APO during pregnancy presented higher levels of complement split product $\mathrm{Bb}$ and sC5b-9 as early as $12-15$ weeks. $\mathrm{Bb}$ and sC5b9 at $12-15$ weeks were significantly associated with APO, after controlling for demographic and clinical risk factors for APO. The adjusted OR for APOs with alternative complement pathway activation, measured by circulating $\mathrm{Bb}$ at $12-15$ weeks of gestation, was increased in patients who were LA-positive or had a history of thrombosis. ${ }^{161}$ Safety data in pregnant women have been published ${ }^{162,163}$ and although numbers are small, eculizumab may eventually be an alternative for treatment during pregnancy in selected APS patients who are at extremely high risk.

\section{Ongoing interventional clinical studies in antiphospholipid antibody-positive patients}

Prospective validation for complement blockade findings from case reports is necessary. New treatment targets from the complement cascade are an alternative that should be further explored. Clinical trials of varying status are detailed below:

1. Terminated due to slow patient enrollment: A Phase IIa for the Treatment of Non-Criteria Manifestations of Antiphospholipid Syndrome: Nephropathy, Thrombocytopenia and Skin ulcers was designed to evaluate safety of an intravenous $\mathrm{C} 5 \mathrm{a}$ inhibitor (ClinicalTrials.gov Identifier: \#NCT02128269).

2. Active not recruiting: Phase II Study of the Use of Eculizumab to Prevent Thrombosis after Renal Transplantation in Patients With a History of Catastrophic Antiphospholipid Antibody Syndrome (CAPS) (ClinicalTrials.gov Identifier: NCT1029587).
3. Completed: Phase II open label study recruiting patients entitled: Eculizumab for Prevention and Treatment of Kidney Graft Reperfusion Injury (ClinicalTrials.gov Identifier: NCT01756508)

\section{Task force recommendations}

Recommendations for clinicians. Anti-complement therapy should be considered in cases of CAPS and refractory microangiopathic disease. Costs are an important limitation that should be taken into account in the decision-making process. Larger clinical trials are required to confirm the findings reported from anecdotal reports and case series. In the meantime, targeting complement is a reasonable alternative that should be considered in selected cases.

Clinical research agenda. Complement inhibition therapy is a promising strategy for patients with microangiopathic APS manifestations. New therapies for targeting complement, including alternative pathway inhibitors, inhibitors of $\mathrm{C} 3, \mathrm{mAbs}$ or small molecules that block $\mathrm{C} 5 \mathrm{aR}$ or $\mathrm{C} 5$ cleavage, and inhibitors that can be localized to areas of inflammation, may provide alternative therapies for APS.

\section{Treatments based on peptides of beta-2-glycoprotein I}

Beta-2-GPI ( $\beta 2 \mathrm{GPI})$ is an antithrombotic plasma protein that has five domains. Proposed new therapies are based either on the C-terminal Domain V or the $\mathrm{N}$-terminal Domain I. This is because the currently accepted theory for pathogenesis of APS proposes that most pathogenic aPL bind $\beta 2$ GPI via Domain I and the aPL-B2GPI complex then binds to phospholipids on cell surfaces via Domain $\mathrm{V}$ leading to thrombosis. ${ }^{164}$

Compared to many other potential novel therapeutic agents for APS (e.g. direct acting anticoagulants and anti-complement drugs), these $\beta 2$ GPI-targeted peptides are less likely to be developed as therapies for other medical conditions. Thus, progress in this field is likely to be a little slower than for more widely applicable agents. There are three major challenges to be overcome in showing that peptide-based therapies have potential utility in APS. These challenges are:

- Prove that the peptide blocks binding in-vitro

- Prove that it blocks pathogenic effects of aPL from patients with APS in-vivo using animal models

- Overcome the issue of short in-vivo half-life of peptide agents. 
None of the agents tested so far has fully overcome all these challenges.

\section{Peptides that target domain $\mathrm{V}$}

The aim of these agents is to block Domain V from binding to cell surfaces. Early work utilised the peptide TIFILFCCSKEKRKKKQAAT, which is derived from cytomegalovirus and has homology to Domain $\mathrm{V}$. In comparison to a control peptide, TIFI reduced binding of $\beta_{2}$ GPI to endothelial cells ${ }^{165}$ and of $\operatorname{IgG}$ from patients with APS (APS- $\operatorname{IgG}$ ) to human trophoblast in-vitro. ${ }^{166}$ Furthermore, TIFI reduced the ability of human aPL to stimulate thrombosis ${ }^{165}$ or fetal loss ${ }^{166}$ in mouse models. However, no new work on TIFI has been presented for some time.

Kolyada and colleagues have developed a dimer of the A1 domain of the apolipoprotein $\mathrm{E}$ receptor (ApoER2). This domain binds Domain V of $\beta_{2} \mathrm{GPI}$, so that the dimer acts as an inhibitor preventing $\beta_{2}$ GPI from binding to cells. In a series of papers this group showed that A1-A1 blocks binding of $\beta_{2}$ GPIanti- $\beta_{2}$ GPI complexes to cardiolipin, ${ }^{167}$ and inhibits the induction of thrombosis by laser both in autoimmune (NZW x BXSB) F1 mice and non-autoimmune $\mathrm{BALB} / \mathrm{c}$ mice infused with human APS-IgG. ${ }^{168}$ In the latter experiment $84 \%$ of A1-A1 was lost from the blood of the mice within an hour. More recently, the group achieved longer-term delivery of A1-A1 in (NZW x BXSB) F1 mice by implanting a subcutaneous osmotic pump. ${ }^{169}$ This led to a reduction in blood pressure in the mice - though this method may not be acceptable to patients. Unlike TIFI, there is currently no evidence that A1-A1 inhibits aPL-induced fetal loss in mice.

\section{Peptides that target domain I}

A group at University College London, UK have used recombinant Domain I produced by bacterial expression, rather than a peptide. Initially wild-type Domain I and a series of point mutants were expressed. ${ }^{170}$ These different products varied in ability to block binding of
APS-IgG to $\beta_{2}$ GPI. In the same mouse model previously used in the TIFI experiments, wild-type Domain I and a high-binding mutant inhibited the ability of APS-IgG to promote thrombosis whereas a mutant with no binding had no such inhibitory effect. ${ }^{171}$ Recombinant Domain I has now been PEGylated in an effort to increase its in-vivo half-life and reduce potential immunogenicity. ${ }^{172}$ A potential disadvantage of PEGylation is reduction of the biological activity of the PEGylated molecule. McDonnell et al, however, have shown that PEGylated Domain I retains the ability of non-PEGylated Domain I to block binding of APS-IgG to $\beta_{2}$ GPI in-vitro and the ability to block thrombosis induced by APS-IgG in-vivo. ${ }^{172}$ The PEGylated product can be produced at $95 \%$ purity, but its half-life in-vivo has not yet been demonstrated and there have been no experiments to investigate whether either PEGylated or non-PEGylated Domain I blocks APS-IgG-induced fetal loss. Table 1 summarises and compares evidence for peptide therapies based on Domain I and Domain V.

\section{Task force recommendations}

Recommendations for clinicians. It is premature to make recommendations regarding the use of peptides of $\beta 2$ GPI for APS.

Clinical research agenda. The key research aims are to take one or more of these agents forward to formal pharmacokinetic and toxicology studies, then to a first-in-man study.

\section{Potential new players}

In pursuit of therapies beyond anticoagulants, APS investigators are increasingly pursuing preclinical and clinical studies with anti-inflammatory and immunomodulatory agents.

Table I. Summary and comparison of evidence for peptide therapies based on Domain I and Domain V.

\begin{tabular}{|c|c|c|}
\hline & Domain I-based treatment & Domain V-based treatments \\
\hline Agents tested & Only recombinant Domain I & Both TIFI and AI-AI dimer \\
\hline Blocks binding in vitro & $\begin{array}{l}\text { Yes - blocks binding of } \\
\text { APS-IgG to } \beta 2 \mathrm{GPI}\end{array}$ & $\begin{array}{l}\text { Yes - blocks binding of } \beta 2 \mathrm{GPI} \\
\text { to cells or cardiolipin. }\end{array}$ \\
\hline $\begin{array}{l}\text { Blocks thrombosis induced } \\
\text { by APS-lgG in vivo }\end{array}$ & Yes & Yes \\
\hline $\begin{array}{l}\text { Blocks fetal loss induced } \\
\text { by APS-IgG in vivo }\end{array}$ & No & Yes (TIFI only) \\
\hline $\begin{array}{l}\text { Measures to increase } \\
\text { half-life in vivo }\end{array}$ & Yes - by PEGylation & $\begin{array}{l}\text { Not for TIFI. AI-AI has not been modified } \\
\text { chemically, but has been administered by } \\
\text { a subcutaneous osmotic pump }\end{array}$ \\
\hline
\end{tabular}




\section{Coenzyme Q10}

An example of such an approach is a recent APS clinical trial utilizing coenzyme Q10 (CoQ10). ${ }^{173}$ CoQ10 participates as an electron carrier in mitochondrial and other membranes, with adequate CoQ10 levels seemingly protecting cells from protein oxidation and lipid peroxidation. In the general population, CoQ10 supplementation decreases the production of proinflammatory cytokines in the context of heart failure and coronary disease. ${ }^{174}$ The APS CoQ10 trial arose from an earlier preclinical study in which the same team demonstrated anti-inflammatory effects (less oxidative stress, less mitochondrial dysfunction) when CoQ10 was added ex vivo to peripheral blood cells of patients with APS. ${ }^{175}$ For the clinical trial, 36 patients with APS were randomized to receive ubiquinol (reduced CoQ10, $200 \mathrm{mg} /$ day) or placebo for one month; approximately $90 \%$ of subjects completed the study. ${ }^{173}$ Among other positive effects, ubiquinol improved endothelial function and decreased monocyte expression of prothrombotic mediators. ${ }^{173}$ Furthermore, ubiquinol ameliorated NET release by neutrophils, while also downregulating neutrophil peroxides. ${ }^{173}$ The authors pointed out that in the absence of clinically significant side effects, and given potential therapeutic benefits, ubiquinol might act as a safe adjunct to standard therapies in APS. ${ }^{173}$

\section{Adenosine receptor agonists}

It has recently been reported that the neutrophils of APS patients have a reduced threshold for the release of NETs (prothrombotic tangles of DNA, histones, and granule-derived proteins expelled from dying neutrophils). ${ }^{176}$ NETs are required for APS-potentiated thrombosis in at least one human/mouse chimeric model of APS. ${ }^{13}$ Furthermore, profiling of APS neutrophils has identified novel therapeutic targets in APS, ${ }^{177}$ including surface adhesion molecules. ${ }^{178}$ Given recent evidence suggesting that the second messenger cyclic AMP (cAMP) may suppress NET release in some contexts, ${ }^{179,180}$ a preclinical study hypothesized that activation of surface adenosine receptors (which trigger cAMP formation in neutrophils) might mitigate the thrombotic manifestations of APS. ${ }^{181}$ Indeed, selective agonism of the adenosine $A_{2 \mathrm{~A}}$ receptor (with CGS21680) appeared to be highly effective in suppressing antiphospholipid antibody-mediated NET release from control neutrophils, as well as spontaneous NET release from APS neutrophils. ${ }^{181}$ In vivo, CGS21680 reduced thrombosis in the inferior vena cavae of both control mice and mice administered aPL. ${ }^{181}$

\section{Adenosine potentiation}

The antithrombotic medication dipyridamole is known to potentiate adenosine signaling by increasing extracellular concentrations of adenosine and also by interfering with the breakdown of cAMP. Similar to CGS21680, dipyridamole appeared to suppress aPLmediated NETosis (in adenosine $\mathrm{A}_{2 \mathrm{~A}}$ receptordependent fashion) and to mitigate venous thrombosis in mice. ${ }^{181}$ While dipyridamole has never been systematically studied in patients with APS, drugs with similar adenosine-amplifying properties such as defibrotide ${ }^{182}$ and dilazep ${ }^{183}$ have been reported as effective in case reports and preclinical models.

Another recent study involved preclinical work in the area of aPL-induced pregnancy morbidity. ${ }^{184}$ Catabolism of extracellular ATP to adenosine by the cell-surface enzymes CD39 and CD73 has antiinflammatory and antithrombotic effects in a number of contexts. ${ }^{185,186}$ In a model involving passive transfer of human antiphospholipid antibodies into pregnant mice, pregnancy morbidity was exacerbated in mice with reduced ability to generate extracellular adenosine due to deficiency of either CD39 or CD73. ${ }^{184}$ In the absence of efficient adenosine generation, the placental decidua demonstrated increased tissue factor expression and complement deposition, as well as elevated oxidative stress and inflammatory cytokines. ${ }^{184}$ The potential for adenosine-mediated signaling to mitigate both thrombosis and pregnancy morbidity in APSrelevant models is intriguing and seems worthy of further investigation.

\section{Other novel approaches}

What other approaches may be on the horizon? One potential area of interest is targeting antibodyproducing cells such as plasmablasts and longer-lived plasma cells. While agents that impact B cells via CD20 or the BAFF/BLyS receptor have not consistently demonstrated reduction in circulating aPL, ${ }^{113,114,128,129}$ it must be noted that these strategies do not directly impact antibody-producing cells. The potential utility of direct plasma cell agents in APS (for example, anti$\mathrm{CD} 38$, as is currently employed for multiple myeloma) was recently emphasized by a preclinical study characterizing lymphocyte subsets of patients with primary APS. ${ }^{187}$ Elegant ex vivo experiments revealed that aPL were still robustly produced by peripheral-blood cells depleted of CD20+ B cells, but not when CD20CD19+ B cells (i.e., CD38-positive plasmablasts) were depleted. ${ }^{187}$

Another target area is the development of antiinterferon therapies, as are being pursued for treatment of SLE. While the so-called interferon signature is 
classically associated with certain rheumatic diseases such as lupus and dermatomyositis, a number of groups have recently detected elevated levels of type I interferons in primary APS, ${ }^{188,189}$ including potential associations with triple positivity and pregnancy morbidity. ${ }^{190}$ Whether neutralization of interferons might mitigate any of the thrombotic - or perhaps more likely non-thrombotic - manifestations of APS awaits further study.

A further area of potential interest is anti-FcRn targeted therapies that are being used in various autoimmune $\operatorname{IgG}$ driven diseases. Efgartigimod is a human IgG1 antibody Fc-fragment, a natural ligand of the neonatal $\mathrm{Fc}$ receptor $(\mathrm{FcRn})$ that blocks $\mathrm{FcRn}$, preventing $\mathrm{IgG}$ recycling, and causing targeted $\mathrm{IgG}$ degradation. In a Phase 2 study in 38 patients with primary immune thrombocytopenia predominantly refractory to previous lines of therapy, efgartigimod was well tolerated and had a favorable safety profile. It induced a rapid reduction of total $\mathrm{IgG}$ levels (mean change from baseline up to $63.7 \%$ ), associated with clinically relevant increases in platelet counts: $46 \%$ patients on efgartigimod vs $25 \%$ on placebo achieved a platelet count of $\geq 50 \times 10^{9} / \mathrm{L}$ on at least two occasions, and $38 \%$ vs $0 \%$ achieved $\geq 50 \times 10^{9} / \mathrm{L}$ for at least 10 cumulative days. There was also a reduced proportion of patients with bleeding. The authors concluded that FcRn antagonism warrants further evaluation as a novel therapeutic approach in ITP. ${ }^{191}$ This approach might be potentially useful in APS.

\section{Task force recommendations}

Recommendations for clinicians. None of the agents discussed in this section should be formally recommended at this time.

Clinical research agenda. The Task Force strongly supports continued preclinical and clinical studies that leverage mechanistic endpoints such as inflammatory biomarkers and aPL levels. The most promising agents should then be considered for large-scale multicenter trials.

\section{Antiphospholipid syndrome treatment trends task force conclusions}

The management of APS is complex and challenging. The importance of the goal to provide optimal care is highlighted by the potentially severe and lifethreatening complications that APS patients can experience, as a result of thrombotic, obstetric and non-criteria manifestations. The lack of clinical trials in APS patients necessitates empirical approaches to try to manage the multiple manifestations of this disorder. Continued work on improving understanding of the pathophysiology of APS is an essential prerequisite to providing a basis and rationale for the development of optimal therapeutic approaches. For meaningful advances in clinical management, a focus on international registries (such as that of APS ACTION), prospective cohort studies and RCTs is essential. The Task Force does not recommend the use of statins in pregnancy in view of their current regulatory status, and the lack of RCTs. APS studies, which need to be appropriately designed and powered, and capture the clinical and laboratory heterogeneity of the syndrome, could eventually provide sufficient high-quality data to underpin evidence-based management. To enable the initiation and development of appropriate clinical studies, there needs to be a focus on devising suitable outcome measures, including a disease activity index, an optimal damage index, and a specific quality of life index.

\section{Declaration of conflicting interests}

The author(s) declared the following potential conflicts of interest with respect to the research, authorship, and/or publication of this article: HC reports, outside the submitted work, institutional research support and support to attend scientific meetings from Bayer Healthcare, with honoraria for lectures from Bayer Healthcare and consultancy fees from UCB paid to University College London Hospitals Charity; DE reports, outside the submitted work, consulting fees from GSK, Exagen and UCB, and research support from American College of Rheumatology, European League Against Rheumatism, Lupus Clinical Trials Consortium, National Institute of Allergy and Infectious Disease, and GSK; JSK reports, outside the submitted work, funding from Jazz Pharmaceuticals for preclinical studies of defibrotide; TLO reports, outside the submitted work, consulting fees from Instrumentation Laboratory and research support from Instrumentation Laboratory and Siemens; AR is a coinventor on a patent to develop PEGylated Domain I of beta2-glycoprotein I as a novel therapy for APS; JE Salmon reports, outside the submitted work, support of an investigator-initiated grant form UCB and consultancy fees from Admirx, Akari, BMS, Realta, and UCB; MGT reports, outside the submitted work, consultant fees and unrestricted grants from AbbVie, MSD, Novartis, Pfizer, GSK and UCB deposited to the Special Account for Research Funding (ELKE) of the National and Kapodistrian University of Athens Medical School; SW reports, outside the submitted work, grant support from Bristol-Meyers-Squibb/Pfizer Alliance paid to Intermountain Healthcare, and service as co-chair for the American College of Chest Physicians panelists guideline update for the treatment of venous thromboembolism; DJW reports, outside the submitted work, being Chief Clinical investigator of the Stamp Trial; and current 
research funding from the UK Medical Research Council, Wellbeing of Women, Chief Scientist Office Scotland, Rosetrees Trust and EGA Charity. MJC, A D-G, DA, DAI and RW have nothing to disclose.

\section{Funding}

The author(s) received no financial support for the research, authorship, and/or publication of this article.

\section{ORCID iDs}

Hannah Cohen (D) https://orcid.org/0000-0003-2032-390X

Ali Duarte-Garcia (D) https://orcid.org/0000-0003-1749-5719

David A Isenberg (D) https://orcid.org/0000-0001-9514-2455

Maria G Tektonidou (D) https://orcid.org/0000-0003-22380975

Scott C Woller (D) https://orcid.org/0000-0002-2522-2705

\section{References}

1. Miyakis S, Lockshin MD, Atsumi T, et al. International consensus statement on an update of the classification criteria for definite antiphospholipid syndrome (APS). J Thromb Haemost 2006; 4: 295-306. doi:10.1111/j.15387836.2006.01753.x

2. Duarte-García A, Pham MM, Crowson CS, et al. The epidemiology of antiphospholipid syndrome: a population-based study. Arthritis Rheumatol 2019; 71: 1545-1552. doi:10.1002/art.40901

3. Cervera R, Piette J-C, Font J, Euro-Phospholipid Project Group, et al. Antiphospholipid syndrome: Clinical and immunologic manifestations and patterns of disease expression in a cohort of 1,000 patients: Clinical and immunologic manifestations of APS. Arthritis Rheum 2002; 46: 1019-1027.

4. Cervera R, Rodríguez-Pintó I and Espinosa G. The diagnosis and clinical management of the catastrophic antiphospholipid syndrome: a comprehensive review. J Autoimmun 2018; 92: 1-11.

5. Erkan D, Aguiar CL, Andrade D, et al. 14th international congress on antiphospholipid antibodies task force report on antiphospholipid syndrome treatment trends. Autoimmun Rev 2014; 13: 685-696.

6. Andrade D, Cervera R, Cohen H, et al. 15th International congress on antiphospholipid antibodies task force on antiphospholipid syndrome treatment trends report. In: Erkan D and Lockshin M (eds) Antiphospholipid syndrome: Current research highlights and clinical insights. New York: Springer, 2017, pp.317-338. ISBN 978-3-319-55442-6.

7. Schreiber K, Sciascia S, de Groot PG, et al. Antiphospholipid syndrome. Nat Rev Dis Primer 2018; 4: 17103 .

8. Willis R and Pierangeli SS. Pathophysiology of the antiphospholipid antibody syndrome. Auto Immun Highlights 2011; 2: 35-52.

9. Cuadrado MJ, López-Pedrera C, Khamashta MA, et al. Thrombosis in primary antiphospholipid syndrome: a pivotal role for monocyte tissue factor expression. Arthritis Rheum 1997; 40: 834-841.

10. Cuadrado MJ, Buendía P, Velasco F, et al. Vascular endothelial growth factor expression in monocytes from patients with primary antiphospholipid syndrome. J Thromb Haemost 2006; 4: 2461-2469.

11. Breen KA, Seed P, Parmar K, Moore GW, Stuart-Smith SE and Hunt BJ. Complement activation in patients with isolated antiphospholipid antibodies or primary antiphospholipid syndrome. Thromb Haemost 2012; 107: 423-429.

12. Arachchillage DRJ, Mackie IJ, Efthymiou M, et al. Rivaroxaban limits complement activation compared with warfarin in antiphospholipid syndrome patients with venous thromboembolism. J Thromb Haemost 2016; 14: 2177-2186.

13. Meng H, Yalavarthi S, Kanthi Y, et al. In vivo role of neutrophil extracellular traps in antiphospholipid antibody-mediated venous thrombosis: in vivo role of NETs in APS. Arthritis Rheumatol 2017; 69: 655-667.

14. Bordin G, Boldorini R and Meroni PL. The two hit hypothesis in the antiphospholipid syndrome: acute ischaemic heart involvement after valvular replacement despite anticoagulation in a patient with secondary APS. Lupus 2003; 12: 851-853.

15. Keeling D, Baglin T, Tait C, et al. British Committee for Standards in Haematology. Guidelines on oral anticoagulation with warfarin - fourth edition: Guideline. $\mathrm{Br} J$ Haematol 2011; 154: 311-324.

16. Tektonidou MG, Andreoli L, Limper M, et al. EULAR recommendations for the management of antiphospholipid syndrome in adults. Ann Rheum Dis 2019; 78: 1296-1304.

17. Cohen H, Hunt BJ, Efthymiou M, et al. Rivaroxaban versus warfarin to treat patients with thrombotic antiphospholipid syndrome, with or without systemic lupus erythematosus (RAPS): a randomised, controlled, openlabel, phase 2/3, non-inferiority trial. Lancet Haematol 2016; 3: e426-e436.

18. Pengo V, Denas G, Zoppellaro G, et al. Rivaroxaban vs warfarin in high-risk patients with antiphospholipid syndrome. Blood 2018; 132: 1365-1371.

19. Ordi-Ros J, Sáez-Comet L, Pérez-Conesa M, et al. Rivaroxaban versus vitamin $\mathrm{K}$ antagonist in antiphospholipid syndrome: a randomized noninferiority trial. Ann Intern Med 2019; 171: 685-694.

20. Woller SC, Stevens SM, Kaplan DA, et al. Apixaban for the secondary prevention of thrombosis among patients with antiphospholipid syndrome: study rationale and design (ASTRO-APS). Clin Appl Thromb Hemost 2016; 22: 239-247.

21. Woller SC, Stevens SM, Kaplan DA, T and Rondina M. Protocol modification of apixaban for the secondary prevention of thrombosis among patients with antiphospholipid syndrome study. Clin Appl Thromb Hemost 2018; 24: 192-192.

22. Legault K, Blostein M, Carrier M, et al. Single-arm pilot feasibility cohort study of rivaroxaban in 
antiphospholipid syndrome. Res Pract Thromb Haemost 2018; 2: 204-205.

23. Crowther MA, Ginsberg JS, Julian J, et al. A comparison of two intensities of warfarin for the prevention of recurrent thrombosis in patients with the antiphospholipid antibody syndrome. $N$ Engl J Med 2003; 349: 1133-1138.

24. Finazzi G, Marchioli R, Brancaccio V, et al. A randomized clinical trial of high-intensity warfarin vs. conventional antithrombotic therapy for the prevention of recurrent thrombosis in patients with the antiphospholipid syndrome (WAPS)1. J Thromb Haemost 2005; 3: 848-853.

25. Malec K, Broniatowska E and Undas A. Direct oral anticoagulants in patients with antiphospholipid syndrome: a cohort study. Lupus 2020; 29: 37-44.

26. Sato T, Nakamura H, Fujieda Y, et al. Factor Xa inhibitors for preventing recurrent thrombosis in patients with antiphospholipid syndrome: a longitudinal cohort study. Lupus 2019; 28: 1577-1582.

27. Sanchez-Redondo J, Espinosa G, Varillas Delgado D and Cervera R. Recurrent thrombosis with direct oral anticoagulants in antiphospholipid syndrome: a systematic literature review and Meta-analysis. Clin Ther 2019; 41: 1839-1862.

28. Dufrost V, Risse J, Reshetnyak T, et al. Increased risk of thrombosis in antiphospholipid syndrome patients treated with direct oral anticoagulants. Results from an international patient-level data Meta-analysis. Autoimmun Rev 2018; 17: 1011-1021.

29. van Es N, Coppens M, Schulman S, Middeldorp S and Büller HR. Direct oral anticoagulants compared with vitamin $\mathrm{K}$ antagonists for acute venous thromboembolism: evidence from phase 3 trials. Blood 2014; 124: 1968-1975.

30. Goldhaber SZ, Eriksson H, Kakkar A, et al. Efficacy of dabigatran versus warfarin in patients with acute venous thromboembolism in the presence of thrombophilia: Findings from RE-COVER ${ }^{\circledR}$, RE $\mathrm{COVER}^{\mathrm{TM}}$ II, and RE-MEDY $^{\mathrm{TM}}$. Vasc Med 2016; 21: 506-514.

31. Kearon C, Parpia S, Spencer FA, et al. Antiphospholipid antibodies and recurrent thrombosis after a first unprovoked venous thromboembolism. Blood 2018; 131: 2151-2160.

32. Miranda S, Park J, Le Gal G, et al. Prevalence of confirmed antiphospholipid syndrome in 18-50 years unselected patients with first unprovoked venous thromboembolism. J Thromb Haemost 2020; 18: 926-930.

33. ten Boekel E and Bartels P. Abnormally short activated partial thromboplastin times are related to elevated plasma levels of TAT, F1+2, D-Dimer and FVIII:C. Pathophysiol Haemost Thromb 2002; 32: 137-142.

34. Schouwers SM, Delanghe JR and Devreese KM. Lupus anticoagulant (Lac) testing in patients with inflammatory status: does $\mathrm{C}$-reactive protein interfere with Lac test results? Thromb Res 2010; 125: 102-104.

35. Tripodi A, Cohen H and Devreese KMJ. Lupus anticoagulant detection in anticoagulated patients. Guidance from the scientific and standardization committee for lupus anticoagulant/antiphospholipid antibodies of the international society on thrombosis and haemostasis. J Thromb Haemost 2020; 18: 1569-1575.

36. Pengo V, Ruffatti A, Del Ross T, et al. Confirmation of initial antiphospholipid antibody positivity depends on the antiphospholipid antibody profile. J Thromb Haemost 2013; 11: 1527-1531.

37. Devignes J, Smaïl-Tabbone M, Hervé A, et al. Extended persistence of antiphospholipid antibodies beyond the 12-week time interval: Association with baseline antiphospholipid antibodies titres. Int $J$ Lab Hematol 2019; 41: 726-730.

38. Stevens SM, Woller SC, Bauer KA, Kasthuri R, et.al. Guidance for the evaluation and treatment of hereditary and acquired thrombophilia. J Thromb Thrombolysis 2016; 41: 154-164.

39. Cohen H, Efthymiou M and Isenberg DA. Use of direct oral anticoagulants in antiphospholipid syndrome: Reply. J Thromb Haemost 2020; 18: 259-261.

40. Tektonidou MG, Andreoli L, Limper M, Tincani A, Ward MM. and Management of thrombotic and obstetric antiphospholipid syndrome: a systematic literature review informing the EULAR recommendations for the management of antiphospholipid syndrome in adults. RMD Open 2019; 5: e000924.

41. Pharmacovigilance Risk Assessment Committee (PRAC). EMA/ PRAC/219985/2019, https://www.ema. europa.eu/en/documents/ prac-recommendation/pracrecommendations-signals-adopted-8- 11-april-2019prac-meeting _en.pdf. 2019 (accessed 11 August 2020).

42. Eliquis $5 \mathrm{mg}$ film-coated tablets film-coated tablets. Summary of Product Characteristics, http://www.medi cines. org.uk/emc/medicine/27220.

43. Lixiana $60 \mathrm{mg}$ Film-Coated Tablets. Summary of Product Characteristics, https://www.medicines.org.uk/ emc/ medicine/30506 (accessed 11 August 2020).

44. Pradaxa $150 \mathrm{mg}$ hard capsules. Summary of Product Characteristics, https://www.medicines.org.uk/emc/ medic one/24839 (accessed 11 August 2020).

45. Xarelto 15 and $20 \mathrm{mg}$ film-coated tablets. Summary of Product Characteristics, https://www.medicines.org.uk/ emc/medicine/25586 (accessed 11 August 2020).

46. Bates SM, Greer IA, Middeldorp S, Veenstra DL, Prabulos A-M and Vandvik PO. VTE, thrombophilia, antithrombotic therapy, and pregnancy. Chest 2012; 141: e691S-e736S.

47. Mak A, Cheung MW-L, Cheak AA.-c and Ho R.-m. Combination of heparin and aspirin is superior to aspirin alone in enhancing live births in patients with recurrent pregnancy loss and positive anti-phospholipid antibodies: a Meta-analysis of randomized controlled trials and meta-regression. Rheumatology (Oxford) 2010; 49: 281-288.

48. Arnaud L, Mathian A, Ruffatti A, et al. Efficacy of aspirin for the primary prevention of thrombosis in patients with antiphospholipid antibodies: an international and collaborative meta-analysis. Autoimmun Rev 2014; 13: 281-291.

49. Arnaud L, Mathian A, Devilliers H, et al. Patient-level analysis of five international cohorts further confirms 
the efficacy of aspirin for the primary prevention of thrombosis in patients with antiphospholipid antibodies. Autoimmun Rev 2015; 14: 192-200.

50. Erkan D, Harrison MJ, Levy R, et al. Aspirin for primary thrombosis prevention in the antiphospholipid syndrome: a randomized, double-blind, placebo-controlled trial in asymptomatic antiphospholipid antibody-positive individuals. Arthritis Rheum 2007; 56: 2382-2391.

51. Gris J-C, Bouvier S, Molinari N, et al. Comparative incidence of a first thrombotic event in purely obstetric antiphospholipid syndrome with pregnancy loss: the NOH-APS observational study. Blood 2012; 119: 2624-2632.

52. Heit JA, Spencer FA and White RH. The epidemiology of venous thromboembolism. J Thromb Thrombolysis 2016; 41: 3-14.

53. Finazzi G. Primary antithrombotic prevention in carriers of antiphospholipid antibodies without systemic autoimmune disorders. Lupus 2012; 21: 747-750.

54. Zuo Y, Barbhaiya M and Erkan D. Primary thrombosis prophylaxis in persistently antiphospholipid antibodypositive individuals: where do We stand in 2018?. Curr Rheumatol Rep 2018; 20: 66.

55. Whitlock EP, Burda BU, Williams SB, Guirguis-Blake JM and Evans CV. Bleeding risks with aspirin use for primary prevention in adults: a systematic review for the U.S. Preventive services task force. Ann Intern Med 2016; 164: 826-835.

56. Ramirez GA, Efthymiou M, Isenberg DA and Cohen H. Under crossfire: thromboembolic risk in systemic lupus erythematosus. Rheumatology (Oxford) 2019; 58: 940-952.

57. Verro P, Levine SR and Tietjen GE. Cerebrovascular ischemic events with high positive anticardiolipin antibodies. Stroke 1998; 29: 2245-2253.

58. APASS Investigators. Antiphospholipid antibodies and subsequent thrombo-occlusive events in patients with ischemic stroke. JAMA 2004; 291: 576-584.

59. Boehringer-Ingelheim. Summary of product characteristics Persantin (dipyridamol) 100mg tablets. The electronic medicines compendium.

60. Espinola RG, Pierangeli SS, Gharavi AE, Harris EN and Ghara AE. Hydroxychloroquine reverses platelet activation induced by human IgG antiphospholipid antibodies. Thromb Haemost 2002; 87: 518-522.

61. Belizna C. Hydroxychloroquine as an anti-thrombotic in antiphospholipid syndrome. Autoimmun Rev 2015; 14: $358-362$.

62. Rand JH, Wu X-X, Quinn AS, et al. Hydroxychloroquine protects the annexin A5 anticoagulant shield from disruption by antiphospholipid antibodies: evidence for a novel effect for an old antimalarial drug. Blood 2010; 115: 2292-2299.

63. Nuri E, Taraborelli M, Andreoli L, et al. Long-term use of hydroxychloroquine reduces antiphospholipid antibodies levels in patients with primary antiphospholipid syndrome. Immunol Res 2017; 65: 17-24.
64. Kravvariti E, Koutsogianni A, Samoli E, Sfikakis PP and Tektonidou MG. The effect of hydroxychloroquine on thrombosis prevention and antiphospholipid antibody levels in primary antiphospholipid syndrome: a pilot open label randomized prospective study. Autoimmun Rev 2020; 19: 102491.

65. Tektonidou MG, Laskari K, Panagiotakos DB and Moutsopoulos HM. Risk factors for thrombosis and primary thrombosis prevention in patients with systemic lupus erythematosus with or without antiphospholipid antibodies. Arthritis \& Rheumatism 2008; 61: 29-36.

66. Erkan D, Unlu O, Sciascia S, APS ACTION, et al. Hydroxychloroquine in the primary thrombosis prophylaxis of antiphospholipid antibody positive patients without systemic autoimmune disease. Lupus 2018; 27: 399-406.

67. Schmidt-Tanguy A, Voswinkel J, Henrion D, et al. Anti-thrombotic effects of hydroxychloroquine in primary antiphospholipid syndrome patients. J Thromb Haemost August 2013; : n/a-n/a.

68. Belizna C, Pregnolato F, Abad S, et al. HIBISCUS: hydroxychloroquine for the secondary prevention of thrombotic and obstetrical events in primary antiphospholipid syndrome. Autoimmun Rev 2018; 17: 1153-1168.

69. Sciascia S, Branch DW, Levy RA, et al. The efficacy of hydroxychloroquine in altering pregnancy outcome in women with antiphospholipid antibodies: Evidence and clinical judgment. Thromb Haemost 2016; 115: 285-290.

70. Sciascia S, Hunt BJ, Talavera-Garcia E, Lliso G, Khamashta MA and Cuadrado MJ. The impact of hydroxychloroquine treatment on pregnancy outcome in women with antiphospholipid antibodies. $\mathrm{Am} \mathrm{J}$ Obstet Gynecol 2016; 214: 273.e1-273-e8.

71. Schreiber K, Schreiber K, Breen K, Cohen H, et al. HYdroxychloroquine to improve pregnancy outcome in women with antiphospholipid antibodies (HYPATIA) protocol: a multinational randomized controlled trial of hydroxychloroquine versus placebo in addition to standard treatment in pregnant women with antiphospholipid syndrome or antibodies. Semin Thromb Hemost 2017; 43: 562-571.

72. Oesterle A, Laufs U and Liao JK. Pleiotropic effects of statins on the cardiovascular system. Circ Res 2017; 120: 229-243.

73. Taylor F, Huffman MD, et al. Statins for the primary prevention of cardiovascular disease. Cochrane heart group, ed. Cochrane Database Syst Rev 2013; Macedo AF. Published online January 31, doi:10.1002/14651858. CD004816.pub5

74. Laloux P. Source: Risks and benefits of statins in stroke secondary prevention. Curr Vasc Pharmacol 2013; 11: 812-816.

75. Glynn RJ, Danielson E, Fonseca FAH, et al. A randomized trial of rosuvastatin in the prevention of venous thromboembolism. N Engl J Med 2009; 360: 1851-1861.

76. Ferrara DE, Swerlick R, Casper K, et al. Fluvastatin inhibits up-regulation of tissue factor expression by 
antiphospholipid antibodies on endothelial cells: Fluvastatin and antiphospholipid-induced tissue factor. J Thromb Haemost 2004; 2: 1558-1563.

77. Meroni PL, Raschi E, Testoni C, et al. Statins prevent endothelial cell activation induced by antiphospholipid (anti-beta2-glycoprotein I) antibodies: effect on the proadhesive and proinflammatory phenotype. Arthritis Rheum 2001; 44(12): 2870-2878.

78. Erkan D, Willis R, Murthy VL, et al. A prospective openlabel pilot study of fluvastatin on proinflammatory and prothrombotic biomarkers in antiphospholipid antibody positive patients. Ann Rheum Dis 2014; 73: 1176-1180.

79. Sciascia S and Bertolaccini M. Thrombotic risk assessment in APS: the global APS score (GAPSS). Lupus 2014; 23: 1286-1287.

80. Radin M, Sciascia S, Erkan D, et al. The adjusted global antiphospholipid syndrome score (aGAPSS) and the risk of recurrent thrombosis: Results from the APS ACTION cohort. Semin Arthritis Rheum 2019; 49: 464-468.

81. Radin M, Schreiber K, Costanzo P, et al. The adjusted global AntiphosPholipid syndrome score (aGAPSS) for risk stratification in young APS patients with acute myocardial infarction. Int J Cardiol 2017; 240: 72-77.

82. Abalos E, Cuesta C, Grosso AL, Chou D and Say L. Global and regional estimates of preeclampsia and eclampsia: a systematic review. Eur J Obstet Gynecol Reprod Biol 2013; 170: 1-7.

83. Girardi G. Pravastatin to treat and prevent preeclampsia. Preclinical and clinical studies. J Reprod Immunol 2017; 124: 15-20.

84. Bateman BT, Hernandez-Diaz S, Fischer MA, et al. Statins and congenital malformations: cohort study. BMJ 2015; 350: h1035-Published 2015 Mar 17.

85. Lefkou E, Mamopoulos A, Dagklis T, Vosnakis C, Rousso D and Girardi G. Pravastatin improves pregnancy outcomes in obstetric antiphospholipid syndrome refractory to antithrombotic therapy. J Clin Invest 2016; 126: 2933-2940.

86. Ahmed A, Williams D, Cheed V, StAmP trial Collaborative Group, et al. Pravastatin for early-onset pre-eclampsia: a randomised, blinded, placebo-controlled trial. BJOG Int Bjog 2020; 127: 478-488.

87. Karalis DG, Hill AN, Clifton S and Wild RA. The risks of statin use in pregnancy: a systematic review. J Clin Lipidol 2016; 10: 1081-1090.

88. Agmon-Levin N, Blank M, Zandman-Goddard G, et al. Vitamin D: an instrumental factor in the antiphospholipid syndrome by inhibition of tissue factor expression. Ann Rheum Dis 2011; 70: 145-150.

89. Andreoli L, Piantoni S, Dall'Ara F, Allegri F, Meroni P and Tincani A. Vitamin D and antiphospholipid syndrome. Lupus 2012; 21: 736-740.

90. Piantoni S, Andreoli L, Allegri F, Meroni PL and Tincani A. Low levels of vitamin D are common in primary antiphospholipid syndrome with thrombotic disease. Reumatismo 2012; 64: 307-313.

91. Riancho-Zarrabeitia L, Cubería M, Muñoz P, et al. Vitamin D and antiphospholipid syndrome: a retrospective cohort study and Meta-analysis. Semin Arthritis Rheum 2018; 47: 877-882.

92. García-Carrasco M, Jiménez-Herrera EA, GálvezRomero JL, et al. The anti-thrombotic effects of vitamin $\mathrm{D}$ and their possible relationship with antiphospholipid syndrome. Lupus 2018; 27: 2181-2189.

93. Laplante P, Fuentes R, Salem D, et al. Anti phospholipid antibody-mediated effects in an arterial model of thrombosis are dependent on toll-like receptor 4. Lupus 2016; 25: 162-176.

94. Gambhir V, Kim J, Siddiqui S, et al. Influence of 1,25-dihydroxy vitamin D3 on TLR4-induced activation of antigen presenting cells is dependent on the order of receptor engagement. Immunobiology 2011;216:988-996.

95. Gualtierotti R, Di Giacomo A, Raschi E, Borghi MO and Meroni PL. Vitamin D and anti-Phospholipid antibody syndrome: a comprehensive review. Open Rheumatol J 2018; 12: 248-260.

96. Willis R, Gonzalez EB and Brasier AR. The journey of antiphospholipid antibodies from cellular activation to antiphospholipid syndrome. Curr Rheumatol Rep 2015; 17: 16.

97. Martinez-Moreno JM, Herencia C, Montes de Oca A, et al. Vitamin D modulates tissue factor and proteaseactivated receptor 2 expression in vascular smooth muscle cells. Faseb J 2016; 30: 1367-1376.

98. Beltowski J, Atanassova P, Chaldakov GN, JamrozWisniewska A, Kula W, Rusek M. Opposite effects of pravastatin and atorvastatin on insulin sensitivity in the rat: role of vitamin D metabolites. Atherosclerosis 2011 219: 526-531.

99. Stephanou A, Ross R and Handwerger S. Regulation of human placental lactogen expression by 1,25-dihydroxyvitamin D3. Endocrinology 1994; 135: 2651-2656.

100. Du H, Daftary GS, Lalwani SI and Taylor HS. Direct regulation of HOXA10 by $1,25-(\mathrm{OH}) 2 \mathrm{D} 3$ in human myelomonocytic cells and human endometrial stromal cells. Mol Endocrinol 2005; 19: 2222-2233.

101. Bodnar LM, Catov JM, Simhan HN, Holick MF, Powers RW and Roberts JM. Maternal vitamin D deficiency increases the risk of preeclampsia. $J$ Clin Endocrinol Metab 2007; 92: 3517-3522.

102. Ota K, Dambaeva S, Han AR, Beaman K, GilmanSachs A and Kwak-Kim J. Vitamin D deficiency may be a risk factor for recurrent pregnancy losses by increasing cellular immunity and autoimmunity. Hum Reprod 2014; 29: 208-219.

103. Soroka N and Talako T. AB0415 the effect of vitamin D supplementation on antiphospholipid antibodies level in patients with antiphospholipid syndrome. Ann Rheum Dis 2016; 75: 1048.2-1048.

104. Scragg R, Stewart AW, Waayer D, et al. Effect of monthly High-Dose vitamin D supplementation on cardiovascular disease in the vitamin $\mathrm{D}$ assessment study : a randomized clinical trial. JAMA Cardiol 2017; 2: 608-616.

105. Pierangeli SS, Colden-Stanfield M, Liu X, Barker JH, Anderson GL and Harris EN. Antiphospholipid antibodies from antiphospholipid syndrome patients 
activate endothelial cells in vitro and in vivo. Circulation 1999; 99: 1997-2002.

106. Merrill JT, Neuwelt CM, Wallace DJ, et al. Efficacy and safety of rituximab in moderately-to-severely active systemic lupus erythematosus: the randomized, doubleblind, phase ii/iii systemic lupus erythematosus evaluation of rituximab trial. Arthritis Rheum 2010; 62: 222-233.

107. Rovin BH, Furie R, Latinis K, LUNAR Investigator Group, et al. Efficacy and safety of rituximab in patients with active proliferative lupus nephritis: the lupus nephritis assessment with rituximab study. Arthritis Rheum 2012; 64: 1215-1226.

108. Hahn BH, McMahon MA, Wilkinson A, American College of Rheumatology, et al. American college of rheumatology guidelines for screening, treatment, and management of lupus nephritis. Arthritis Care Res (Hoboken) 2012; 64: 797-808.

109. Fanouriakis A, Kostopoulou M, Alunno A, et al. 2019 Update of the EULAR recommendations for the management of systemic lupus erythematosus. Ann Rheum Dis 2019; 78: 736-745.

110. https://www.england.nhs.uk/wp-content/uploads/2018/ 07/Rituximab-for-the-treatment-of-systemic-lupuserythematosus-in-adults.pdf (accessed 7 March 2020).

111. Wang CR, Weng CT, Liu MF. Monocentric experience of the rituximab therapy in systemic lupus erythematosus-associated antiphospholipid syndrome with warfarin therapy failure. Semin Arthritis Rheum 2017; 47: e7-e8.

112. Chalam KV, Gupta SK and Agarwal S. Rituximab effectively reverses papilledema associated with cerebral venous sinus thrombosis in antiphospholipid antibody syndrome. Eur J Ophthalmol 2007; 17: 867-870.

113. Adamson R, Sangle S, Kaul A, et al. Clinical improvement in antiphospholipid syndrome after rituximab therapy. J Clin Rheumatol 2008; 14: 359-360. DOI: 10.1097/RHU.0b013e31818f38d4.

114. Erkan D, Vega J, Ramón G, Kozora E and Lockshin MD. A pilot open-label phase II trial of rituximab for non-criteria manifestations of antiphospholipid syndrome. Arthritis Rheum 2013; 65: 464-471.

115. Ioannou $Y$, Lambrianides A, Cambridge G, Leandro MJ, Edwards JCW and Isenberg DA. B cell depletion therapy for patients with systemic lupus erythaematosus results in a significant drop in anticardiolipin antibody titres. Ann Rheum Dis 2007; 67: 425-426.

116. Gamoudi D, Cutajar M, Gamoudi N, Camilleri DJ and Gatt A. Achieving a satisfactory clinical and biochemical response in antiphospholipid syndrome and severe thrombocytopenia with rituximab: two case reports. Clin Case Rep 2017; 5: 845-848.

117. Gkogkolou P, Ehrchen J and Goerge T. Severe antiphospholipid antibody syndrome - response to plasmapheresis and rituximab. J Dermatolog Treat 2017; 28: 564-566.
118. Cartin-Ceba R, Peikert T, Ashrani A, et al. Primary antiphospholipid Syndrome-Associated diffuse alveolar hemorrhage: Outcomes of primary APS-Associated DAH. Arthritis Care Res (Hoboken) 2014; 66: 301-310.

119. Yachoui R, Sehgal R, Amlani B and Goldberg JW. Antiphospholipid antibodies-associated diffuse alveolar hemorrhage. Semin Arthritis Rheum 2015; 44: 652-657.

120. Helgeson SA, Heckman AJ, McCain JD, Cowart JB, Maniaci MJ and Garland JL. A 32-year-old man with hypoxemia and bilateral upper-lobe predominant ground-glass infiltrates on chest imaging. Oxf Med Case Rep 2018; 2018doi:10.1093/omcr/omy072

121. Aakjær S, Bendstrup E, Ivarsen $P$ and Madsen LB. Continous rituximab treatment for recurrent diffuse alveolar hemorrhage in a patient with systemic lupus erythematosus and antiphosholipid syndrome. Respir Med Case Rep 2017; 22: 263-265.

122. Berman H, Rodríguez-Pintó I, Cervera R, Catastrophic Antiphospholipid Syndrome (CAPS) Registry Project Group (European Forum on Antiphospholipid Antibodies), et al. Rituximab use in the catastrophic antiphospholipid syndrome: descriptive analysis of the CAPS registry patients receiving rituximab. Autoimmun Rev 2013; 12: 1085-1090.

123. Diószegi Á, Tarr $\mathrm{T}$, Nagy-Vincze $\mathrm{M}$, et al. Microthrombotic renal involvement in an SLE patient with concomitant catastrophic antiphospholipid syndrome: the beneficial effect of rituximab treatment. Lupus 2018; 27: 1552-1558.

124. Rymarz A and Niemczyk S. The complex treatment including rituximab in the management of catastrophic antiphospholid syndrome with renal involvement. $B M C$ Nephrol 2018; 19: 132.

125. Abisror N, Mekinian A, Brechignac S, Ruffatti A, Carbillon L and Fain O. Inefficacy of plasma exchanges associated to rituximab in refractory obstetrical antiphospholipid syndrome. Presse Med 2015; 44: 100-102.

126. Baker KP, Edwards BM, Main SH, et al. Generation and characterization of LymphoStat-B, a human monoclonal antibody that antagonizes the bioactivities of B lymphocyte stimulator. Arthritis Rheum 2003; 48: 3253-3265.

127. Sciascia S, Rubini E, Radin M, Cecchi I, Rossi D and Roccatello D. Anticardiolipin and anti-beta 2 glycoprotein-I antibodies disappearance in patients with systemic lupus erythematosus and antiphospholipid syndrome while on belimumab. Ann Rheum Dis 2018; 77: 1694-1695.

128. Emmi G, Bettiol A, Palterer B, et al. Belimumab reduces antiphospholipid antibodies in SLE patients independently of hydroxychloroquine treatment. Autoimmun Rev 2019; 18: 312-314.

129. Chatzidionysiou K, Samoli E, Sfikakis PP and Tektonidou MG. Effect of belimumab treatment on antiphospholipid antibody levels: post-hoc analysis based on two randomised placebo-controlled trials in systemic lupus erythematosus. Ann Rheum Dis 2020; 79: 304-307. 
130. Yazici A, Yazirli B and Erkan D. Belimumab in primary antiphospholipid syndrome. Lupus 2017; 26: 1123-1124.

131. Lockshin MD, Kim M, Laskin CA et al. Prediction of adverse pregnancy outcome by the presence of lupus anticoagulant, but not anticardiolipin antibody, in patients with antiphospholipid syndrome. Arthritis and Rheumatism 2012; 64: 2311-2318.

132. Kim MY, Buyon JP, Guerra MM, et al. Angiogenic factor imbalance early in pregnancy predicts adverse outcomes in patients with lupus and antiphospholipid antibodies: results of the PROMISSE study. Am J Obstet Gynecol 2016; 214: 108.e1-108.e14.

133. Gelber SE, Brent E, Redecha P, et al. Prevention of defective placentation and pregnancy loss by blocking innate immune pathways in a syngeneic model of placental insufficiency. J Immunol 2015; 195: 1129-1138.

134. Alijotas-Reig J, Esteve-Valverde E, Llurba E, et al. Treatment of refractory poor aPL-related obstetric outcomes with TNF-alpha blockers: Maternal-fetal outcomes in a series of 18 cases. Semin Arthritis Rheum 2019; 49: 314-318.

135. Hemmati I and Kur J. Adalimumab-associated antiphospholipid syndrome: a case report and review of the literature. Clin Rheumatol 2013; 32: 1095-1098.

136. Cheemalavagu S, McCoy SS and Knight JS. Digital ischaemia secondary to adalimumab-induced antiphospholipid syndrome. BMJ Case Rep 2020; 13: e232907.

137. Bećarević M. Detrimental roles of TNF-alpha in the antiphospholipid syndrome and de novo synthesis of antiphospholipid antibodies induced by biopharmaceuticals against TNF-alpha. J Thromb Thrombolysis 2017; 44: $565-570$.

138. Dlott JS and Roubey RAS. Drug-Induced lupus anticoagulants and antiphospholipid antibodies. Curr Rheumatol Rep 2012; 14: 71-78. https://doi.org/10. 1007/s11926-011-0227-1.

139. Hennessey A, Lukawska J, Cambridge G, Isenberg D and Leandro M. Adverse infusion reactions to rituximab in systemic lupus erythematosus: a retrospective analysis. BMC Rheumatol 2019; 3: 32.

140. Pierangeli SS, Vega-Ostertag M, Liu $X$ et al. Complement activation: a novel pathogenic mechanism in the antiphospholipid syndrome. Ann NY Acad Sci 2005; 1051: 413-420.

141. Girardi G, Berman J, Redecha P, et al. Complement C5a receptors and neutrophils mediate fetal injury in the antiphospholipid syndrome. J Clin Invest 2003; 112: 1644-1654.

142. Hillmen P, Hall C, Marsh JCW, et al. Effect of eculizumab on hemolysis and transfusion requirements in patients with paroxysmal nocturnal hemoglobinuria. $N$ Engl J Med 2004; 350: 552-559.

143. Salmon JE, Giradi G, Holers VM. Complement activation as a mediator of antiphospholipid antibody induced pregnancy loss and thrombosis. Ann Rheum 2002; 61 (Suppl II): ii46-ii50.
144. Ritis K, Doumas M, Mastellos D, et al. A novel C5a Receptor-Tissue factor Cross-Talk in neutrophils links innate immunity to coagulation pathways. $J$ Immunol 2006; 177: 4794-4802.

145. Redecha P, Tilley R, Tencati M, et al. Tissue factor: a link between $\mathrm{C} 5 \mathrm{a}$ and neutrophil activation in antiphospholipid antibody induced fetal injury. Blood 2007; 110: 2423-2431.

146. Salmon JE and Girardi G. Antiphospholipid antibodies and pregnancy loss: a disorder of inflammation. J Reprod Immunol 2008; 77: 51-56.

147. Girardi G, Redecha P and Salmon JE. Heparin prevents antiphospholipid antibody-induced fetal loss by inhibiting complement activation. Nat Med 2004; 10: $1222-1226$.

148. Lonati PA, Scavone M, Gerosa M, et al. Blood CellBound $\mathrm{C} 4 \mathrm{~d}$ as a marker of complement activation in patients with the antiphospholipid syndrome. Front Immunol 2019; 10: 773.

149. Rand JH, Wu XX, Wolgast LR, Lei V and Conway EM. A novel 2-stage approach that detects complement activation in patients with antiphospholipid antibody syndrome. Thromb Res 2017; 156: 119-125.

150. Lonze BE, Singer AL and Montgomery RA. Eculizumab and renal transplantation in a patient with CAPS. N Engl J Med 2010; 362: 1744-1745.

151. Hadaya K, Ferrari-Lacraz S, Fumeaux D, et al. Eculizumab in acute recurrence of thrombotic microangiopathy after renal transplantation: Eculizumab, TMA and kidney transplantation. Am J Transplant 2011; 11: 2523-2527.

152. Shapira I, Andrade D, Allen SL and Salmon JE. Brief report: Induction of sustained remission in recurrent catastrophic antiphospholipid syndrome via inhibition of terminal complement with eculizumab. Arthritis Rheum 2012; 64: 2719-2723.

153. Canaud G, Kamar N, Anglicheau D, et al. Eculizumab improves posttransplant thrombotic microangiopathy due to antiphospholipid syndrome recurrence but fails to prevent chronic vascular changes: Eculizumab and antiphospholipid syndrome recurrence. Am J Transplant 2013; 13: 2179-2185.

154. Bakhtar O, Thajudeen B, Braunhut BL, et al. A case of thrombotic microangiopathy associated with antiphospholipid antibody syndrome successfully treated with eculizumab. Transplantation 2014; 98: e17-e18.

155. Kronbichler A, Frank R, Kirschfink M, et al. Efficacy of eculizumab in a patient with ImmunoadsorptionDependent catastrophic antiphospholipid syndrome: a case report. Medicine (Baltimore) ). 2014; 93: e143.

156. Zikos TA, Sokolove J, Ahuja N and Berube C. Eculizumab induces sustained remission in a patient with refractory primary catastrophic antiphospholipid syndrome. J Clin Rheumatol 2015; 21: 311-313.

157. Strakhan M, Hurtado-Sbordoni M, Galeas N, Bakirhan $\mathrm{K}$, Alexis K and Elrafei T. 36-year-old female with catastrophic antiphospholipid syndrome treated with 
eculizumab: a case report and review of literature. Case Rep Hematol 2014; 2014: 704371.

158. Chaturvedi S, Braunstein EM, Yuan X, et al. Complement activity and complement regulatory gene mutations are associated with thrombosis in APS and CAPS. Blood 2020; 135: 239-251.

159. Morales JM, Martinez-Flores JA, Serrano M, et al. Association of early kidney allograft failure with preformed IgA antibodies to $\beta 2$-glycoprotein I. J Am Soc Nephrol 2015; 26: 735-745.

160. Gustavsen A, Skattum L, Bergseth G, et al. Effect on mother and child of eculizumab given before caesarean section in a patient with severe antiphospholipid syndrome: a case report. Medicine (Baltimore) ). 2017; 96: e6338.

161. Kim MY, Guerra MM, Kaplowitz E, et al. Complement activation predicts adverse pregnancy outcome in patients with systemic lupus erythematosus and/or antiphospholipid antibodies. Ann Rheum Dis 2018; 77: 549-555.

162. Kelly RJ, Höchsmann B, Szer J, et al. Eculizumab in pregnant patients with paroxysmal nocturnal hemoglobinuria. N Engl J Med 2015; 373: 1032-1039.

163. Stefanovic V. The extended use of eculizumab in pregnancy and complement activation-associated diseases affecting maternal, fetal and neonatal Kidneys-The future is now? JCM 2019; 8: 407.

164. Giannakopoulos B, Passam F, Rahgozar S and Krilis SA. Current concepts on the pathogenesis of the antiphospholipid syndrome. Blood 2007; 109: 422-430.

165. Ostertag MV, Liu X, Henderson V and Pierangeli SS. A peptide that mimics the vth region of beta2-glycoprotein I reverses antiphospholipid-mediated thrombosis in mice. Lupus 2006; 15: 358-365.

166. de la Torre YM, Pregnolato F, D'Amelio F, et al. Antiphospholipid induced murine fetal loss: novel protective effect of a peptide targeting the $\beta 2$ glycoprotein I phospholipid-binding site. Implications for human fetal loss. J Autoimmun 2012 May; 38: J209-15.

167. Kolyada A, Lee CJ, De Biasio A and Beglova N. A novel dimeric inhibitor targeting Beta2GPI in Beta2GPI/antibody complexes implicated in antiphospholipid syndrome. Uversky VN, ed. PLoS ONE 2010; 5: e15345.

168. Kolyada A, Porter A and Beglova N. Inhibition of thrombotic properties of persistent autoimmune anti$\beta 2$ GPI antibodies in the mouse model of antiphospholipid syndrome. Blood 2014; 123: 1090-1097.

169. Kolyada A, Ke Q, Karageorgos I, et al. Soluble analog of ApoER2 targeting beta2-glycoprotein I in immune complexes counteracts hypertension in lupus-prone mice with spontaneous antiphospholipid syndrome. J Thromb Haemost 2016; 14: 1298-1307.

170. Ioannou Y, Pericleous C, Giles I, Latchman DS, Isenberg DA and Rahman A. Binding of antiphospholipid antibodies to discontinuous epitopes on domain I of human $\beta 2$-glycoprotein I: Mutation studies including residues R39 to R43. Arthritis Rheum 2007; 56: 280-290.

171. Ioannou Y, Romay-Penabad Z, Pericleous C, et al. In vivo inhibition of antiphospholipid antibody-induced pathogenicity utilizing the antigenic target peptide domain I of beta2-glycoprotein I: proof of concept. J Thromb Haemost 2009; 7: 833-842.

172. McDonnell TCR, Willis R, Pericleous C, et al. PEGylated domain I of beta-2-Glycoprotein I inhibits the binding, coagulopathic, and thrombogenic properties of IgG from patients with the antiphospholipid syndrome. Front Immunol 2018; 9: 2413.

173. Pérez-Sánchez C, Aguirre MÁ, Ruiz-Limón P, et al. Ubiquinol effects on antiphospholipid syndrome prothrombotic profile: a randomized, Placebo-Controlled trial. Arterioscler Thromb Vasc Biol 2017; 37: 1923-1932.

174. Garrido-Maraver J, Cordero MD, Oropesa-Avila M, et al. Clinical applications of coenzyme Q10. Front Biosci (Landmark Ed) 2014; 19: 619-633. Published 2014 Jan 1, doi:10.2741/4231.

175. Perez-Sanchez C, Ruiz-Limon P, Aguirre MA, et al. Mitochondrial dysfunction in antiphospholipid syndrome: implications in the pathogenesis of the disease and effects of coenzyme Q10 treatment. Blood 2012; 119: 5859-5870.

176. Yalavarthi S, Gould TJ, Rao AN, et al. Release of neutrophil extracellular traps by neutrophils stimulated with antiphospholipid antibodies: a newly identified mechanism of thrombosis in the antiphospholipid syndrome: Release of NETs by neutrophils stimulated with APL. Arthritis Rheumatol 2015; 67: 2990-3003.

177. Knight JS, Meng H, Coit P, et al. Activated signature of antiphospholipid syndrome neutrophils reveals potential therapeutic target. JCI Insight 2017; 2: e93897.

178. Sule G, Kelley WJ, Gockman K, et al. Increased adhesive potential of antiphospholipid syndrome neutrophils mediated by $\beta 2$ integrin mac-1. Arthritis Rheumatol 2020; 72: 114-124.

179. Eby JC, Gray MC and Hewlett EL. Cyclic AMPMediated suppression of neutrophil extracellular trap formation and apoptosis by the Bordetella pertussis adenylate cyclase toxin. Blanke SR, ed. Infect Immun 2014; 82: $5256-5269$.

180. Shishikura K, Horiuchi T, Sakata N, et al. Prostaglandin $\mathrm{E}_{2}$ inhibits neutrophil extracellular trap formation through production of cyclic AMP: PGE 2 inhibits neutrophil NET formation. $\mathrm{Br} J$ Pharmacol 2016; 173: 319-331.

181. Ali RA, Gandhi AA, Meng H, et al. Adenosine receptor agonism protects against NETosis and thrombosis in antiphospholipid syndrome. Nat Commun 2019; 10: 1916.

182. Burcoglu-O'Ral A, Erkan D and Asherson R. Treatment of catastrophic antiphospholipid syndrome with defibrotide, a proposed vascular endothelial cell modulator. J Rheumatol 2002; 29: 2006-2011. 
183. Zhou H, Wolberg AS and Roubey RAS. Characterization of monocyte tissue factor activity induced by IgG antiphospholipid antibodies and inhibition by dilazep. Blood 2004; 104: 2353-2358.

184. Samudra AN, Dwyer KM, Selan C, et al. CD39 and CD73 activity are protective in a mouse model of antiphospholipid antibody-induced miscarriages. J Autoimmun 2018; 88: 131-138.

185. Yadav V, Chi L, Zhao R, et al. ENTPD-1 disrupts inflammasome IL-1 $\beta$-driven venous thrombosis. $J$ Clin Invest 2019; 129: 2872-2877.

186. Knight JS, Mazza LF, Yalavarthi S, et al. Ectonucleotidase-mediated suppression of lupus autoimmunity and vascular dysfunction. Front Immunol 2018; 9: 1322.

187. Hisada R, Kato M, Sugawara E, et al. Circulating plasmablasts contribute to antiphospholipid antibody production, associated with type I interferon upregulation. J Thromb Haemost 2019; 17: 1134-1143.
188. Grenn RC, Yalavarthi S, Gandhi AA, et al. Endothelial progenitor dysfunction associates with a type I interferon signature in primary antiphospholipid syndrome. Ann Rheum Dis 2017; 76: 450-457.

189. Xourgia E and Tektonidou MG. Type I interferon gene expression in antiphospholipid syndrome: Pathogenetic, clinical and therapeutic implications. $J$ Autoimmun 2019; 104: 102311.

190. Flessa CM, Vlachiotis S, Nezos A, Andreakos E, Mavragani CP and Tektonidou MG. Independent association of low IFN $\lambda 1$ gene expression and type I IFN score/IFN $\lambda 1$ ratio with obstetric manifestations and triple antiphospholipid antibody positivity in primary antiphospholipid syndrome. Clin Immunol 2019; 209: 108265.

191. Newland AC, Sánchez-González B, Rejtő L, et al. Phase 2 study of efgartigimod, a novel FcRn antagonist, in adult patients with primary immune thrombocytopenia. Am J Hematol 2020; 95: 178-187. 